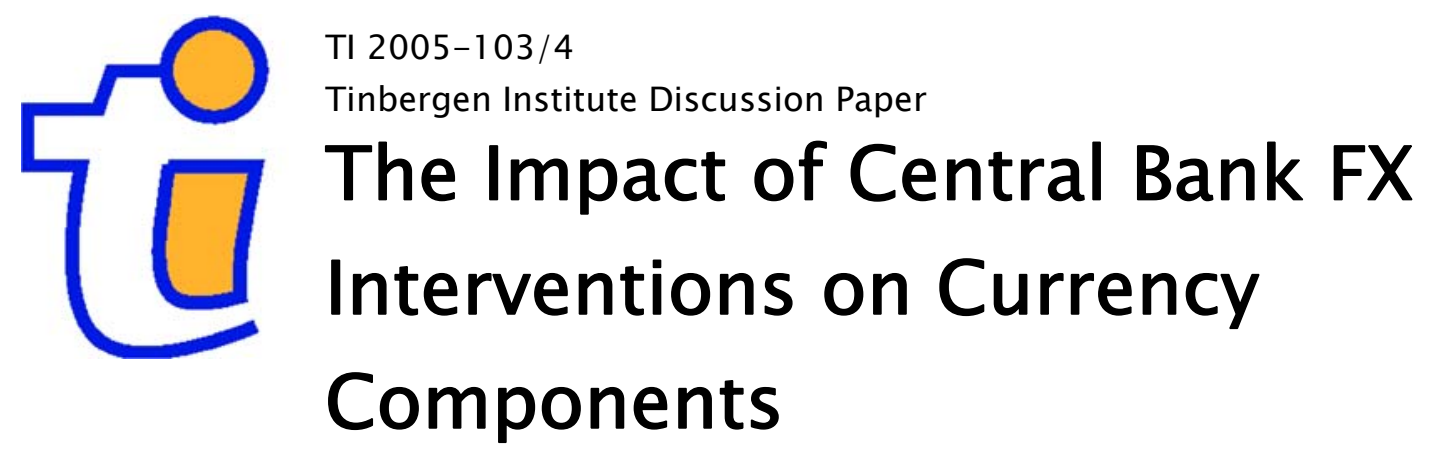

\author{
Michel Beine \\ Charles S. Bos² \\ Sebastien Laurent ${ }^{3}$
}

1 University of Luxemburg (Luxemburg), and Free University of Brussels (Belgium);

2 Vrije Universiteit Amsterdam, and Tinbergen Institute (The Netherlands);

3 University of Namur, and CORE (Belgium). 


\section{Tinbergen Institute}

The Tinbergen Institute is the institute for economic research of the Erasmus Universiteit Rotterdam, Universiteit van Amsterdam, and Vrije Universiteit Amsterdam.

Tinbergen Institute Amsterdam

Roetersstraat 31

1018 WB Amsterdam

The Netherlands

Tel.: $\quad+31(0) 205513500$

Fax: $\quad+31(0) 205513555$

Tinbergen Institute Rotterdam

Burg. Oudlaan 50

3062 PA Rotterdam

The Netherlands

Tel.: $\quad+31(0) 104088900$

Fax: $\quad+31(0) 104089031$

Please send questions and/or remarks of nonscientific nature to driessen@tinbergen.nl.

Most TI discussion papers can be downloaded at http://www.tinbergen.nl. 


\title{
The impact of central bank FX interventions on currency components*
}

\author{
Michel BEINE† Charles S. BOS ${ }^{\ddagger}$ and Sébastien LAURENT ${ }^{\S}$
}

September 13, 2005

\begin{abstract}
This paper is the first attempt to assess the impact of official FOREX interventions of the three major central banks in terms of the dynamics of the currency components of the major exchange rates (EUR/USD and YEN/USD) over the period 1989-2003. We identify the currency components of the mean and the volatility processes of exchange rates using the recent Bayesian framework developed by Bos and Shephard (2004). Our results show that in general, the concerted interventions tend to affect the dynamics of both currency components of the exchange rate. In contrast, unilateral interventions are found to primarily affect the currency of the central bank present in the market. Our findings also emphasize a role for interventions conducted by these central banks on other related FOREX markets.
\end{abstract}

${ }^{*}$ This paper has benefited from useful comments and particular suggestions of V. Bodart, B. Candelon, G. Chortareas, E. Girardin, C. Neely, G. Prat and from participants of conferences in Aarhus, New York, Luxembourg, Strasbourg and Maastricht. Of course, the usual disclaimer applies.

${ }^{\dagger}$ University of Luxemburg (Luxemburg) and Free University of Brussels (Belgium); mbeine@ulb.ac.be.

${ }^{\ddagger}$ Tinbergen Institute and Vrije Universiteit Amsterdam (The Netherlands); cbos@feweb.vu.nl.

${ }^{\S}$ University of Namur and CORE (Belgium); sebastien.laurent@fundp.ac.be. 


\section{Introduction}

The use of direct interventions in the FX market remains a stabilisation instrument in the hand of the central banks of the major industrialized cuntries. While the Federal Reserve (Fed hereafter) has been increasingly reluctant to rely on such interventions since 1995, the other major central banks have recently been involved in such a policy. In 2000, the European Central Bank (ECB) conducted a round of sales of foreign currency aimed at supporting the Euro (EUR) against the US Dollar (USD). In recent years, the Bank of Japan (BoJ) has been extremely active in the FX markets, proceeding to massive sales of its currency against both the USD and the Euro. As a piece of evidence, over the year 2003 only, the BoJ was present in the markets during 82 business days and purchased more than 20 billions of USD.

Given the extensive use of these central bank interventions (CBIs), a large empirical literature has tried to assess their efficiency, both in terms of exchange rate level and volatility. Due to the release of the official data by the three major central banks, most analyses have relied on the financial econometric approaches based on daily and even intra-daily data. Extensive reviews of this literature are provided among others by Sarno and Taylor (2001) and Humpage (2003). On the whole, the literature sheds some doubt about the efficiency of this instrument. While little evidence has been found that direct sales or purchases of foreign currency succeed in driving the exchange rate in the desired direction, most studies using high frequency data (weekly, daily or intra-daily data) conclude that such operations result in increased exchange rate volatility. Another robust finding emphasises that while concerted operations tend to move the market, unilateral interventions exert some limited impact on the dynamics of exchange rates.

Explanations of the empirical results have been provided mainly by referring to the signalling theory. The signalling channel (Mussa 1981) states that by intervening, the central banks convey some private information about fundamentals to market participants and therefore tend to alter their expectations in terms of future values of the exchange rate. Such a theory stresses the case for potential asymmetric effects of interventions depending on their intrinsic features. In this respect, an important distinction concerns unilateral versus concerted operations. Along the signalling hypothesis, interventions carried out by a single central bank should mainly affect the dynamics of the currency of the central bank present in the market. In contrast, concerted interventions should be seen more as market-wide events that can affect the value of both currencies. Testing for the existence of such asymmetric effects is the primary aim of this paper.

We revisit the analysis of the short-run impact of CBIs conducted by the major central banks (the US Fed, the ECB, or Bundesbank (BB) before the introduction of the Euro, and the BoJ) in the foreign exchange market over the recent period (1989-2003). Unlike the rest of the literature, we focus on the impact on the currency components of the exchange rates rather than on the exchange rate itself. The level and the volatility of these (unobserved) currency components are identified using the recent Bayesian modelling approach proposed by Bos and Shephard (2004). This approach extends the early development of Mahieu and Schotman (1994) and involves the estimation of a state-space model with a series of stochastic volatility processes. Our analysis allows to express each exchange rate as the combination of two unobserved currency factors whose moments can be investigated along with the CBIs taking place in the market.

In short, the central topics of interest are the possible asymmetry of CBIs, the existence of a dollar bias in the effects, and the importance of interventions in auxiliary markets for the 
analysis.

On the whole, our results support the existence of asymmetric effects between unilateral and concerted operations. We find that while coordinated operations affect the volatility of both currencies, unilateral interventions lead to an increase only in the currency component of the central bank present in the market. The traditional analysis in terms of exchange rates turns out to be unable to isolate this last effect. With the alternative identification in terms of currency components of the effect of CBIs we show that limited, unilateral operations can still exert significant effects in terms of currency volatility. To the extend that a rise in uncertainty might be considered detrimental, this result suggests that even unilateral interventions yield some counterproductive effects.

The paper is organized as follows. Section 2 reviews the empirical literature on the impact of CBIs and clarifies the nature of our contribution. Section 3 presents both the model and the estimation procedure, comments on the extracted country specific components and provides some insight on the quality of the volatility measures of the extracted currency components. Section 4 details our empirical approach, provides the findings and interprets the results. Section 5 summarises the conclusions, and points the way for future extensions of this research project.

\section{The state of the literature and contribution of the paper}

\subsection{Previous empirical findings}

The release of high frequency data on their FX interventions by the major central banks has induced the development of an extensive empirical literature aimed at capturing the impact of such operations on the dynamics of exchange rates. Recent works including Sarno and Taylor (2001), Humpage (2003) or Dominguez (2004) have fortunately provided some reviews of this large literature. Different econometric approaches have been proposed to capture the effects of CBIs, including event studies and parametric models. Due to emphasis on the impacts in terms of exchange rate uncertainty, different approaches to measure volatility have been used: GARCH models (Dominguez 1998), implied volatility modelling (Bonser-Neal and Tanner 1996, Beine 2004) or more recently realized volatility (Beine, Laurent and Palm 2004). While the bulk of the empirical analyses has studied the impact using daily data, some recent approaches have investigated the impact in an intra-daily perspective (Dominguez 2003, Payne and Vitale 2003).

As emphasised by several authors, there is no clear consensus in the literature concerning the efficiency of these CBIs. While Dominguez (2003) and Payne and Vitale (2003) find some robust effects of CBIs in the very short run on the level of exchange rate returns, most studies conducted at the daily frequency find either insignificant or mixed results. ${ }^{1}$ The results in terms of exchange rate volatility seem much more clear-cut, pointing out that in general, direct interventions tend to raise exchange rate volatility. This holds for daily data although some recent evidence (Dominguez 2003, Beine et al. 2004) find that these volatility effects might be mean reverting within a couple of hours.

\footnotetext{
${ }^{1} \mathrm{~A}$ number of papers (see among others Beine, Bénassy-Quéré and Lecourt 2002) document even perverse effects on the returns. These perverse effects have been rationalised by some theoretical contributions emphasising the role of the interaction process between the central bank and the market traders (Bhattacharya and Weller 1997)
} 
Another feature of this empirical literature is that the results tend to be dependent on the involved currency markets as well as on the sample period under investigation. This is hardly surprising given that exchange rate policies varies over time and across central banks. As an example, while the ECB and the Federal Reserve have been increasingly reluctant to intervene in the FX markets after 1995, the BoJ activity in the FX markets has reached a peak in 2003. As another example, while the BoJ tended to use a transparent policy before 2003, it might have recently favoured secret interventions (Beine and Lecourt 2004).

Most of these empirical findings concerning the effects of official interventions have been rationalised using the signalling theory (Mussa 1981). The interventions under investigation have been reported by the central banks to be sterilised, which rules out any monetary channel. The portfolio channel has also received very little support, which is understandable given the relative small amounts used by the central banks in these operations. ${ }^{2}$ The signalling theory states that through these interventions, central banks convey some fundamental information about their future policies. Along the signalling channel, the unilateral interventions carried out by a central bank should signal private information mainly useful to assess the future value of its currency. There is much less rationale that such operations aims at conveying any valuable information relative to the other currencies. In this respect, our analysis which disentangles the impact of CBIs into currency components provides a useful way to test further the signalling channel as the main channel at work to explain their effects.

\subsection{Contribution of the paper}

The general contribution of this paper is to focus on the impact of interventions on the currency dynamics rather that on the exchange rate evolution. There are three main reasons calling for the adoption of an analysis in terms of currency components. In turn, this approach enables to provide answers to three specific questions concerning the impact of CBIs in the FX markets.

First, unlike certain financial events like oil price increases, foreign exchange CBIs are by definition country specific or geographical area specific events. For instance, a sale of Japanese Yen (YEN) by the Bank of Japan is expected to impact primarily the value of the Yen against all the currencies, especially when such operations are not concerted, i.e. when they involve a single central bank. This idea is consistent with the popular flexible-price monetary model (Frenkel 1976) in which the value of the nominal exchange rate is related to the difference of future expected values of domestic and foreign variables such as the money stock, output and interest rates. Depending on whether these CBIs are unilateral or concerted the signalling content about these variables will be differnt, inducing therefore a different impact on the dynamics of the exchange rate.

The statistical investigation in terms of currencies or country components rather than in terms of exchange rates can therefore shed some interesting light on particular effects of these CBIs and on asymmetric effects associated to different types of operations. Basically, the empirical literature finds less impact of unilateral rather than concerted operations, especially in terms of volatility. ${ }^{3}$ Given the differentiated content carried out by these operations, one

\footnotetext{
${ }^{2}$ A notable exception is Evans and Lyons (2001). Their analysis nevertheless applies to primarily secret interventions, i.e. unreported official interventions which represent a rather small proportion of the interventions carried out by the three major central banks over this period.

${ }^{3}$ See among others Dominguez (1998) and Beine et al. (2004). It should be emphasised that while the impact of unilateral interventions is generally lower than the one obtained for concerted operations, it has
} 
reason for this result could be that an intervention from a given central bank will mostly impact the country component of the exchange rate of the active central bank, without much effect on the component of the counterpart country. Testing for such an effect is only possible after some clear identification of the currency component. In a nutshell, we try to answer the following question:

Question 1 Is there some evidence of asymmetric effects between unilateral and concerted operations in terms of currency dynamics?

Second, most analyses of CBIs conducted in the context of flexible exchange rate regimes involve the USD currency. When it comes to CBIs, this choice is a natural one because the dollar is often the currency against which foreign central banks try to stabilize the value of their currency. Furthermore, the investigation of the USD allows to make a clear distinction between coordinated and unilateral operations. ${ }^{4}$ Once more, such a distinction stems from the different signalling content conveyed by these two types of interventions. While the choice of the USD is rational, it might nevertheless be dangerous to draw general conclusions on the impact of these interventions, given the special situation of the USD as the world leading currency. The USD is by far the most liquid currency, especially for spot transactions. ${ }^{5}$ Detken and Hartman (2000) discuss the various features involving the international role of currencies (financing and investment roles), with a special emphasis on the changes associated with the inception of the Euro. They document the leading position of the USD in all segments, especially during the period before 1999 in which the Fed and the Bundesbank were active on the markets. Disentangling the impact in terms of currencies rather than in terms of exchange rates might therefore be useful to assess the part of the results related to the special situation of the USD. In other words, we address the second following question:

Question 2 Is there a dollar effect driving the empirical results regarding the effects of CBIs?

A third and important contribution is the way one controls for what is called auxiliary interventions in the FX markets. Auxiliary interventions are interventions involving a particular currency but occurring on another market. Infra-marginal interventions in the context of the European Monetary System (EMS) provide a good example of these auxiliary interventions. ${ }^{6}$ The massive sales of Deutsche Mark (DEM) by the Bundesbank against some European currencies (like the Italian Lira, the Spanish Peseta or the French Frank) during the 1992/3 EMS crisis might have impacted the DEM against the USD. However, while it is tedious to find a clear rationale for introducing these interventions in a classical exchange rate equation of the DEM/USD, it is more straightforward to allow for some impact on the DEM currency component. In turn, this ensures a better control for other type of news in the model and hence a better estimation of these CBI effects. Our analysis therefore aims at answering a third question:

\footnotetext{
been found to be statistically significant for some of these operations.

${ }^{4}$ Basically, the YEN/USD and the EUR/USD markets are the only liquid markets on which concerted interventions have taken place over the recent period. A given intervention is considered as concerted if it is carried out by the two involved central banks the same day and in the same direction. Such a situation is partly due to the strategy of the Fed favouring these two important markets.

${ }^{5}$ The triennial survey on FX markets conducted by the Bank for International Settlements (BIS, 2001) shows that over the 1989-2001, the USD entered on average on one side of $86.6 \%$ of all foreign exchange transactions, against 38 and $23.48 \%$ for the Euro and the YEN, respectively. The 2004 survey yields very similar figures.

${ }^{6}$ The other case considered in this paper concerns unilateral YEN sales of the BoJ against the Euro.
} 
Question 3 Should one account for interventions on auxiliary markets when analysing the impact of FX operations in the major markets?

\section{Modelling exchange rates in factors}

\subsection{Exchange rate data}

Our dataset contains hourly data for three major exchange rates (four currencies), the Japanese Yen, the Euro (with corresponding Deutsche Mark value before the introduction of the Euro in 1999) and the British Pound (GBP) against the US Dollar. For these three exchange rates, we have about 14.5 years of intraday (hourly) data, from January 11989 to May 31 2003. The raw data consists of all interbank EUR/USD, YEN/USD and GBP/USD bid-ask quotes displayed on the Reuters FX screen during this period. The series are presented in Figure 1.

As standard in the literature, we compute hourly exchange rate prices $S_{t, i j}(Q)$ at time $t$, quoted at hour $Q=0, \ldots, 23 \mathrm{GMT}+1$ between currencies $i$ and $j$ from the linearly interpolated average of the logarithms of bid and ask quotes for the two ticks immediately before and after the hourly time stamps throughout the global 24-hour trading day. Next we obtain daily and intradaily returns as the first difference of the logarithmic daily or intradaily prices, multiplied by 100 for ease of presentation whenever convenient.
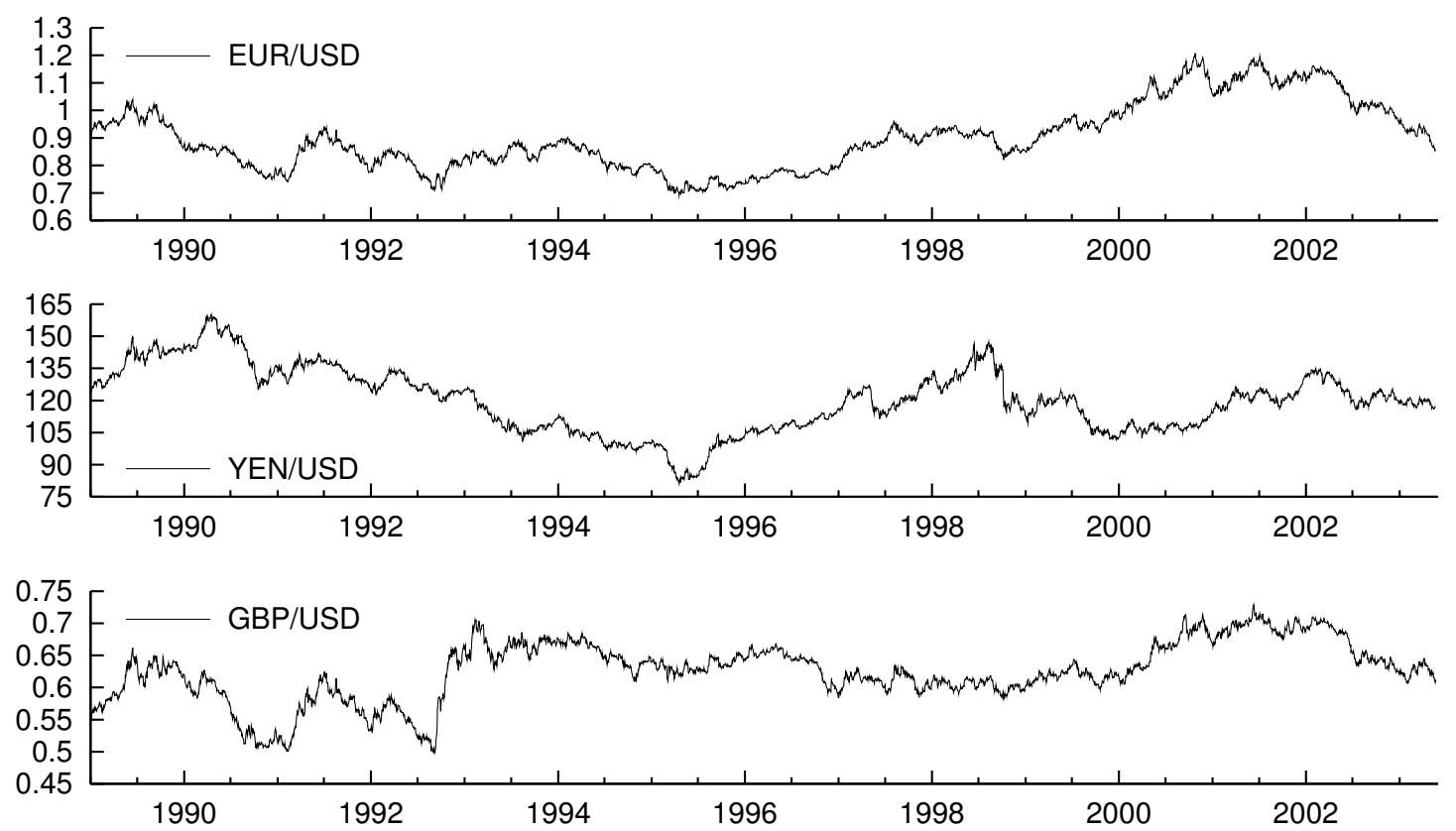

Figure 1: Daily exchange rates EUR/USD, YEN/USD and GBP/USD over the 1989-2003 period, quoted at $Q=16 \mathrm{~h} 00 \mathrm{GMT}+1$ 


\subsection{The model}

\section{Exchange rates}

Current models in the exchange rate literature tend to model the exchange rates between currencies $i$ and $j$ at time $t S_{t, i j}$ directly, possibly after taking the first difference of its logarithms. ${ }^{7}$ For multivariate models, using $S_{t, i j}$ and $S_{t, i k}$ for countries $i, j$ and $k$ jointly, this induces a strong source of correlation, as both exchange rates involve the common currency $i$.

Mahieu and Schotman (1994) propose to model each underlying unobserved currency factor separately, thus explicitly taking the correlation in exchange rates along. Each exchange rate $S_{t, i j}$ (e.g. EUR/USD) at time $t$ between currencies $i$ and $j$ comprises information on the two currencies $E_{t, i}$ (e.g. EUR) and $E_{t, j}$ (e.g. USD), as

$$
S_{t, i j}=\frac{E_{t, i}}{E_{t, j}}
$$

or, in logarithms,

$$
s_{t, i j}=e_{t, i}-e_{t, j}
$$

with $s_{t, i j}=\log S_{t, i j}, e_{t, i}=\log E_{t, i}$. These factors capture the evolution of currencies $i$ and $j$ with respect to the other ones included in the statistical model. They might be viewed therefore as some kid of index capturing the strength of the currencies. If such a decomposition into country factors is made, it becomes possible to distinguish the effect of CBIs on each of the currencies separately.

\section{Multivariate system of exchange rates}

It is inherently impossible, given only one exchange rate, to extract both underlying factors. Each increase or drop in $s_{t, i j}$ can be caused by either a change in $e_{t, i}$, in $e_{t, j}$, or by a combination of changes in both. Nevertheless, from the correlation structure between two (log-) exchange rates $s_{t, i j}$ and $s_{t, k j}$ it is possible to unravel the factors, though some degree of uncertainty about the exact value of the factors always persists after the estimation. Using more than two exchange rates improves the estimability of the system.

In what follows, we use a series of $n$ exchange rates vis-à-vis a common currency, in practice the USD. This common denominator will take index 0 , leading us to model $n+1$ country factors. Including cross-rates of currencies $i, j \neq 0$ in the system does not add any further information, as the relation holds that $s_{t, i j} \equiv s_{t, i 0}-s_{t, j 0}$. Therefore, knowledge of the values of the (log-) exchange rates $s_{t, i 0}$ and $s_{t, j 0}$ includes all information on the exchange rate $s_{t, i j}$.

\section{Currency factors and volatility}

Before the factors can be extracted, a further assumption about the evolution of the underlying factors needs to be made. The basic assumption is to allow the factors to evolve according to a random walk (which implies the assumption of unpredictable returns on the exchange rates),

\footnotetext{
${ }^{7}$ Note that, for ease of presentation, we do not specify the quotation time of the exchange rates in this section.
} 
with independent normal disturbances. Stochastic volatility (SV) components (Harvey, Ruiz and Shephard 1994, Jacquier, Polson and Rossi 1994) govern the variance of the series. The country factors evolve along the following lines:

$$
\begin{array}{rlrl}
e_{t+1, i} & =\beta_{t, i}+e_{t, i}+\epsilon_{t, i}, & t=0, \ldots, T, \\
\epsilon_{t, i} & \sim \mathcal{N}\left(0, \exp \left(h_{t, i}\right)\right), & i=0, \ldots, n, \\
h_{t+1, i}-\gamma_{t+1, i} & =\phi_{i}\left(h_{t, i}-\gamma_{t, i}\right)+\xi_{t, i}, & & \\
\xi_{t, i} & \sim \mathcal{N}\left(0, \sigma_{\xi, i}^{2}\right) & &
\end{array}
$$

The stochastic volatility specification for the variances of the random walk disturbances allows for more flexibility than the standard deterministic GARCH specification (Bos, Mahieu and Van Dijk 2000, Carnero, Peña and Ruiz 2001), as there is an additional element of random variation in the model. This point will be further commented on in Section 3.4. The drawback of allowing for stochastic volatility however is that the estimation tends to be much more computationally demanding. This seems to be the main reason that relatively few applications have appeared in the literature.

The assumptions for the country factors imply a random walk structure for the logarithm of the exchange rates as well, with an intricate correlation of first and second moments of the exchange rate returns due to the combination of the country factors for level and volatility. The implied structure for the exchange rates is consistent with the findings of the literature on the impossibility of predicting the level of exchange rates (certainly at longer horizons), but with clear persistence in the variance.

\section{Interventions}

Both the random walk equation (2) and the stochastic volatility equation (4) allow for a time varying mean $\beta_{t, i}$ and $\gamma_{t, i}$ to model the baseline mean and variance as well as the effects of the interventions of the central banks $W_{t, i}$. We model

$$
\begin{aligned}
\beta_{t, i} & =W_{t, i} \beta_{i}, \\
\gamma_{t, i} & =\gamma_{0 i}+\left|W_{t, i}\right| \gamma_{i},
\end{aligned}
$$

with $W_{t, i}$ a vector of indicators for the different interventions affecting the currency at time $t$ (see Section 4.1), and $\beta, \gamma$ the corresponding vectors of parameters. By convention, the indicators take the value 0 when there is no intervention, -1 or 1 in case of a sale or a purchase of USD respectively on a specific currency market. For the auxiliary interventions, i.e. those not involving the USD, -1 and 1 correspond to the purchase or sale of the own currency by the intervening central bank. The equation for $\gamma_{t, i}$ includes an overall constant $\gamma_{0 i}$ to govern the baseline variance, and only takes the timing, not the direction, of interventions into account.

\section{Disturbances}

The disturbances $\epsilon_{t, i}$ are taken independent across time $t$ and countries $i$. As exchange rate returns themselves show little or no autocorrelation, the underlying factor increments can reasonably be assumed independent across time.

The independence across countries is a different issue. One can imagine that a global crisis has a negative effect on all or some currencies jointly. Tims and Mahieu (2003) introduce a 
'world factor' influencing all exchange rates, such as to allow for some correlation between currencies. An alternative approach would be to allow the disturbances $\epsilon_{t, i}$ and $\epsilon_{t, j}$ be correlated directly; this is left for further research as it strongly complicates the computational process, and is not necessary to address the issues raised in this article.

\subsection{Unobserved components and estimation}

The system of exchange rates is build up from unobserved components describing the level of the currency factors $e_{t, i}$ and their volatility $h_{t, i}$. Such a setup allows for estimation in state-space form (Harvey 1989, Durbin and Koopman 2001). As the dependence on the volatility factors is non-linear, the standard linear Gaussian filtering equations are not valid. Estimation of models with combined level and volatility components is involved. We follow the Bayesian setup explained in Bos and Shephard (2004), which improves on earlier Bayesian Gibbs samplers for stochastic volatility models as in Jacquier et al. (1994) and Harvey et al. (1994). Appendix B gives a more profound insight into the sampling procedure, but the following could serve as an outline.

In the Gibbs sampling scheme use is made of data augmentation: Apart from the model parameters $\theta=\left(\sigma_{\xi}, \phi, \gamma, \beta\right)$ also the unknown state elements of the level, e, and volatility, $\mathbf{h}$, are considered as vectors of parameters. In Bos and Shephard (2004) it is proposed to use the volatility disturbances $u_{t, i}=\xi_{t, i} / \sigma_{\xi, i}$ (which are a function of $\mathbf{h}$ and $\theta$ ) instead of the volatility sequences $\mathbf{h}$ themselves; this leads to a strong improvement in the speed of convergence of the sampling algorithm.

The parameters are sampled in turn, from the full conditional posterior density. For instance, the levels e are sampled from their posterior density $p(\mathbf{e} \mid \theta, \mathbf{u}, \mathbf{s})$, conditioning on the other parameters (including volatility disturbances $u$ ) and the observed exchange rates $\mathbf{s}$. As, conditional on $\theta, \mathbf{u}, \mathbf{s}$, the model is linear and Gaussian, the standard simulation smoother (Durbin and Koopman 2002) delivers a sample from the currency levels e.

Each posterior density is a combination of the likelihood and a prior density of the parameters. Based on earlier experience we fix an Inverted Gamma prior-density for the parameters $\sigma_{\xi, i}$ with expectation and standard deviation of 0.2 ; for $\phi_{i}$ the prior is a Beta, with expectation 0.86 and standard deviation 0.1 , and all intervention and mean parameters get normal priors centered at zero with standard deviation 2. Such priors are informative in the sense that no problems with non-existing posteriors can occur, but vague enough to allow the data to choose the location and spread of the posterior density.

The appendix provides more detail of the other full conditional densities and the sampling scheme. After sampling each of the parameters in turn, for a large number of iterations, a collection of drawings of the parameters results which describes the available information on these parameters, on their location, uncertainty, correlation, etc.

All estimations in this paper are performed using code written by the authors, using a combination of Ox (Doornik 2001), SsfPack (Koopman, Shephard and Doornik 1999, for the volatility models), and the G@RCH package (Laurent and Peters 2005, for the GARCH models).

\subsection{A look at the extracted components}

While a detailed examination of the posterior densities of the model parameters is postponed until Appendix C, it is at this stage informative to present estimates of the currency factors 
and related volatilities. Figures 2 and 3 plot the extracted factors obtained after the estimation of equations (2)-(4) without intervention. Each of the plots displays the evolution of the posterior mean of the level $e_{t, i}$ or volatility factor $\sigma_{t, i}=\exp \left(h_{t, i} / 2\right)$, and a 1-standard deviation error bound. The index numbers between parentheses identify the time of occurrence of the financial events listed in Table 1, which will be discussed below.
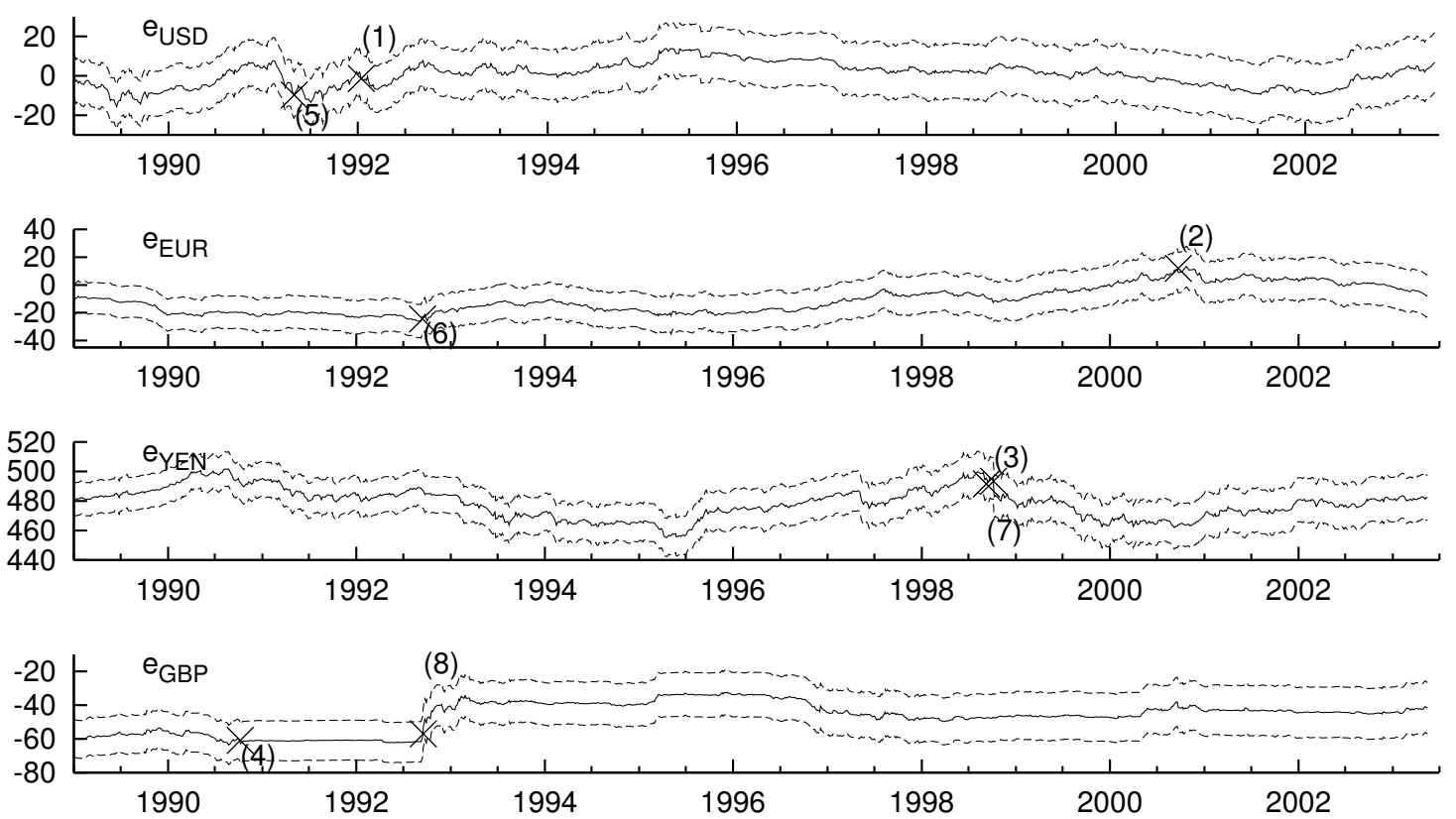

Figure 2: Posterior mean of level factors $e_{t, i}$ extracted for the currencies, with a one-standard deviation error bound; the numbers between parentheses refer to events in Table 1

In order to illustrate the relevance of these extracted factors, it is interesting to proceed to some preliminary analysis. We conduct three types of illustrations: (i) we isolate important financial events identified through the inspection of the variation in the factors $e_{t, i}$ and $h_{t, i}$; (ii) we carry out a regression analysis of the different volatility measures; (iii) we assess the sensitivity of the extracted factors to the addition of the fourth currency in the estimation procedure.

\section{Financial events}

Figure 2, which plots the level of the currency factors, suggests that the USD has globally appreciated between 1995 and 2001. It also captures the steady depreciation trend of the Euro after its inception in 1999 until halfway 2001, and reproduces the sharp depreciation of the GBP following its exit from the EMS. Figure 3 uncovers interesting patterns of currency volatility. In particular, it shows that the long-term volatility of the USD has decreased since 1991 and is on average lower than the one of the Euro and the YEN. The graphs in the second and fourth panels depict the effects of the EMS crisis in September 1992. Interestingly, the impact of this crisis is not visible in the factors peculiar to the USD and the YEN, which makes sense since the EMS crisis primarily affected the European currencies. Also, the figure 

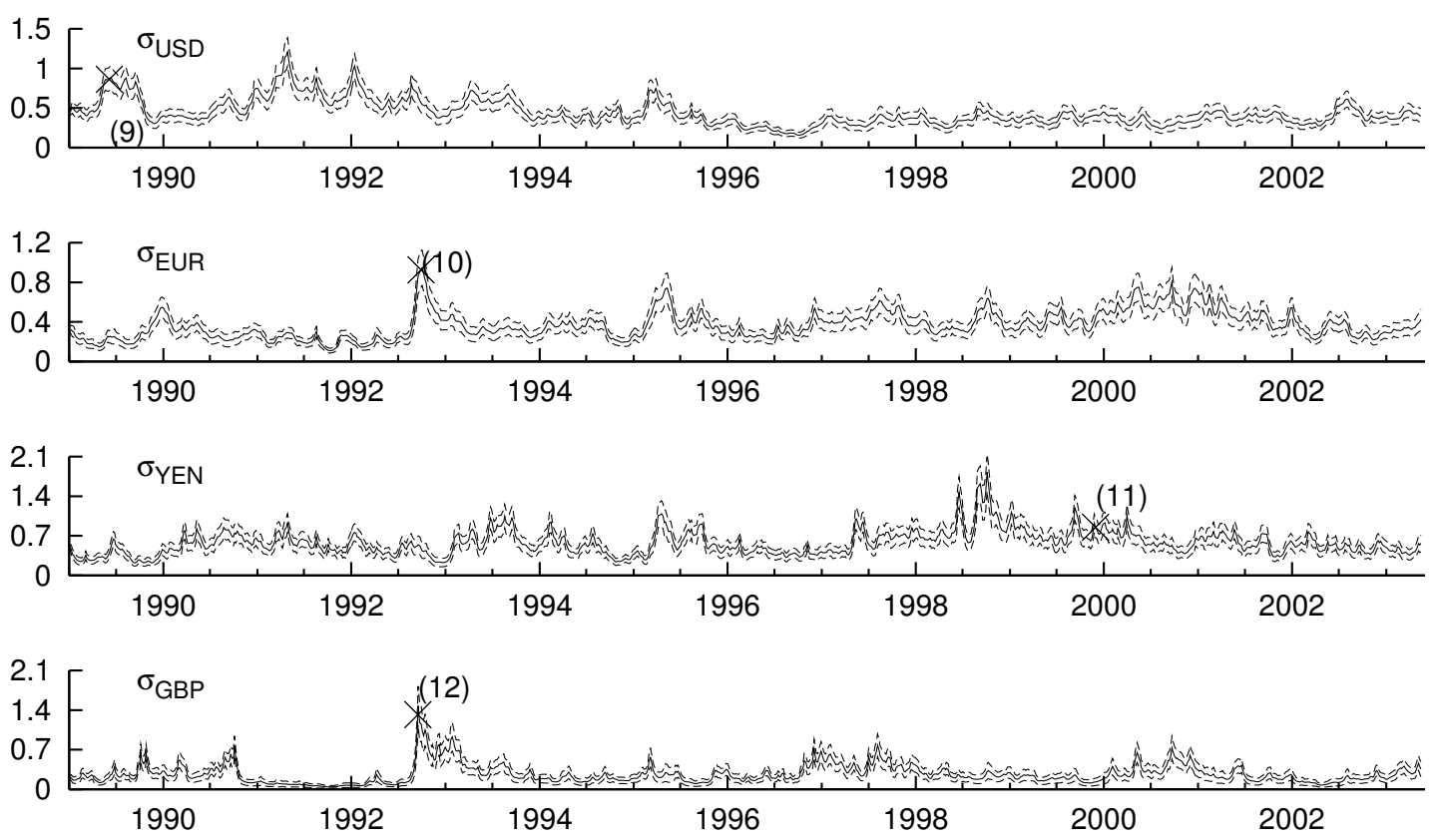

Figure 3: Posterior mean of volatility factors $\sigma_{t, i}=\exp \left(h_{t, i} / 2\right)$ extracted for the currencies, with a one-standard deviation error bound; the numbers between parentheses refer to events in Table 1

shows that the pound was more affected that the Euro, which is meaningful since the British currency was at the heart of the EMS troubles at the time. To sum up, the factors allow to uncover patterns specific to the dynamics of the currencies which are not always directly observable from the evolution of exchange rates.

In a more systematic way, the ability of the factors to capture sharp variations of currencies can be illustrated by the identification of important events. To illustrate that, using the Factiva online events database (see http://www.factiva.com), we isolate the most important events associated to extreme variations in these currency factors. In particular, we pick up the days of the largest appreciation, largest depreciation and highest surge in volatility of each currency implied by the extracted factors and isolate the most reported event on that particular day. Table 1 reports the days and the associated event, while these are also indicated in Figures 2 and 3. The table suggests that the sharp variation of these factors correspond to major financial events known to exert important impacts on the exchange rate. Interestingly, the majority of these particular events are country-specific or currency-specific events, i.e. shocks peculiar to a specific country or currency like unilateral interventions or key interest rates variations. This illustrates that the evolution of factors captures idiosyncratic dynamics of currencies.

\section{Volatility regressions}

The main purpose of the paper it to quantify the impact of CBIs on the country specific factors described by the SV model with unobserved components, i.e. equations (2) and (4). As surveyed by Humpage (2003), GARCH-type models have been extensively used in the 
Table 1: Extracted currency components and event study

\begin{tabular}{lccl}
\hline Currency & Date & Index & Event \\
\hline \multicolumn{2}{l}{ Largest appreciation } & & \\
USD & $01-15-92$ & $(1)$ & 61 points surge in the Dow Jones \\
EUR & $09-22-00$ & $(2)$ & Concerted ECB intervention \\
YEN & $10-07-98$ & $(3)$ & Reported Japanese repatriation of funds \\
GBP & $10-08-90$ & $(4)$ & Entry in the EMS \\
\hline Largest & depreciation & & \\
USD & $05-01-91$ & $(5)$ & Interest rate cut by the Fed \\
EUR & $09-14-92$ & $(6)$ & Interest rate cut by the BB \\
YEN & $09-09-98$ & $(7)$ & First interest rate cut in 3 years \\
GBP & $09-17-92$ & $(8)$ & Leaves the EMS; interest rate cut of $2 \%$ \\
\hline Largest volatility increase & \\
USD & $06-06-89$ & $(9)$ & Unilateral Fed intervention \\
EUR & $09-28-92$ & $(10)$ & EMS crisis \\
YEN & $11-30-99$ & $(11)$ & BoJ Unilateral BOJ intervention \\
GBP & $09-16-92$ & $(12)$ & EMS crisis \\
\hline
\end{tabular}

The table reports the dates of the largest variations in the currency factors, along with the reported events according to the Factiva data base. The index numbers refer to the indices in Figures 2-3.

empirical literature and might be considered as a useful benchmark to assess the contribution of our analysis. For the sake of comparison with the SV factors models, we propose to rely on the Exponential GARCH model of Nelson (1991) (EGARCH hereafter) since it ensures a positive variance, which might be useful when news variables (such as CBIs) are supposed to impact the volatility dynamics.

Defining the exchange return $r_{t, i j}$ as $r_{t, i j}=s_{t, i j}-s_{t-1, i j}$, the $\operatorname{EGARCH}(1,1)$ model is specified as follows

$$
\begin{aligned}
r_{t, i j} & =\beta_{t, i j}^{\dagger}+\epsilon_{t, i j}, \\
\epsilon_{t, i j} & \equiv \exp \left(h_{t, i j} / 2\right) z_{t, i j}, \quad z_{t, i j} \sim \mathcal{N}(0,1), \\
h_{t, i j} & =\gamma_{t, i j}^{\dagger}+\vartheta_{1, i j}^{\dagger} z_{t-1, i j}+\vartheta_{2, i j}^{\dagger}\left[\left|z_{t-1, i j}\right|-E\left(\left|z_{t, i j}\right|\right)\right]+\delta_{1, i j} h_{t-1, i j},
\end{aligned}
$$

where $\vartheta_{1, i j}^{\dagger}, \vartheta_{2, i j}^{\dagger}$ and $\delta_{1, i j}^{\dagger}$ are parameters governing the evolution of the GARCH process. The CBIs, which will be used in Section 4, are introduced both in the conditional mean and variance equations. They follow a similar setup as in the SV model (see equations (6) and (7)). The interventions influence equations (8)-(9) through

$$
\begin{aligned}
& \beta_{t, i j}^{\dagger}=\beta_{0, i j}^{\dagger}+W_{t, i j} \beta_{1, i j}^{\dagger}, \\
& \gamma_{t, i j}^{\dagger}=\gamma_{0, i j}^{\dagger}+\left|W_{t, i j}\right| \gamma_{1, i j}^{\dagger},
\end{aligned}
$$

where $W_{t, i j}$ is a vector of indicators identical to the one used in equations (6) and (7). $\beta_{i j}^{\dagger}=\left(\beta_{0, i j}^{\dagger}, \beta_{1, i j}^{\dagger}\right)$ and $\gamma_{i j}^{\dagger}=\left(\gamma_{0, i j}^{\dagger}, \gamma_{1, i j}^{\dagger}\right)$ are the corresponding vectors of parameters. Unlike the SV model, these two vectors of parameters capture the effect of CBIs on the dynamics of the exchange rate returns or the EUR, YEN and GBP vis-à-vis the USD rather than in terms 
of the country specific components. The estimation of the model is done by quasi-maximum likelihood using the G@RCH 4.0 package (see Laurent and Peters 2005).

No universally acceptable loss function exists for the ex-post comparison of highly nonlinear forecasts. Following Andersen and Bollerslev (1998), we assess the relative forecasting performances of the EGARCH and SV models through the analysis of the value of the coefficient of multiple correlation, or $R^{2}$, in a Mincer-Zarnowitz regression approach (see Mincer and Zarnowitz 1969). We nevertheless need a benchmark measure of volatility to assess the quality of these regressions. A traditional measure for the observed volatility in the literature is the square of the returns or the absolute returns (Pagan and Schwert 1990). However, in a recent paper dealing with daily volatility, Andersen and Bollerslev (1998) have shown that this measure is not fully relevant and have proposed an alternative measure. This new measure uses cumulated squared intradaily returns, also called realized volatility, which is a more precise measure of the daily volatility. Following these authors, we compute the daily realized volatility as:

$$
\operatorname{RV}_{t, i j}(Q)=\sum_{k=0}^{23} r_{t, i j, Q-k}^{2}
$$

where $r_{t, i j, Q}$ denotes the intraday hourly return of the corresponding exchange rate peculiar to day $t$ between quotation time $Q-1$ and $Q$ (by convention $r_{t, i j,-Q}=r_{t-1, i j, 24-Q}$ for $Q=1,2, \ldots, 23)$.

For a given quotation time $Q$ (we drop the $Q$ index for the sake of simplicity in the notations), we project $\mathrm{RV}_{t, i j}$ on a constant and the in-sample one-step-ahead forecast of $h_{t, i j}$, denoted $F_{t, i j \mid t-1}$, based on the EGARCH(1,1) model of Nelson (1991) or on the SV model with unobserved components. ${ }^{8}$ More specifically the Mincer-Zarnowitz regression takes the following form:

$$
\mathrm{RV}_{t, i j}=a+b F_{t, i j \mid t-1}+u_{t}, \quad t=1, \ldots, T .
$$

Note that for the SV model, since the country components are assumed independent, $F_{t, i j \mid t-1} \equiv$ $\widehat{\exp \left(h_{t, i}\right)}+\operatorname{exp(h_{t,j})}$. The forecasts of the factor standard deviations $\operatorname{exp(h_{t,i})}$ are extracted from a run of the particle filter (Pitt and Shephard 1999) at the posterior mode of the parameters of the model.

Recently, Andersen, Bollerslev and Meddahi (2005) have shown that the $R^{2}$ of the MincerZarnowitz regression (13) based on the realized volatility underestimates the true predictability of the competing models. To overcome this problem, they propose a simple methodology (based on the recent non-parametric asymptotic distributional results in Barndorff-Nielsen and Shephard 2002) to obtain an adjusted $R^{2}$, denoted $\bar{R}^{2}$, that takes into account the measurement errors in the realized volatility.

Table 2 reports the estimated parameters of the Mincer-Zarnowitz regressions (robust standard errors are given between parentheses) as well as the $\bar{R}^{2}$ 's and $R^{2}$ 's (between brackets) of both the EGARCH $(1,1)$ model and the SV model (without CBIs dummies) estimated on the three daily exchange rates vis-à-vis the USD, at quotation time $Q=16 \mathrm{~h} 00 \mathrm{GMT}+1$.

From Table 2, one hardly sees a difference between the two competing approaches in terms of bias. Indeed, irrespective of the specification, $a$ and $b$ are not significantly different from 0

\footnotetext{
${ }^{8}$ We do not investigate the out-of-sample performance of these models since the models are only used to quantify the impact of interventions.
} 
Table 2: In-sample forecast comparison

\begin{tabular}{l|ccc|ccc}
\hline \multicolumn{9}{|c}{ Mincer-Zarnowitz Regressions } \\
\hline Series & \multicolumn{3}{c}{ EGARCH $(1,1)$} & \multicolumn{3}{c}{ SV } \\
\hline \multirow{3}{*}{ EUR/USD } & $\hat{a}$ & $\hat{b}$ & $\bar{R}^{2}\left[R^{2}\right]$ & $\hat{a}$ & $\hat{b}$ & $\bar{R}^{2}\left[R^{2}\right]$ \\
& -0.08 & 1.28 & $\mathbf{0 . 1 9}$ & -0.10 & 1.34 & $\mathbf{0 . 3 8}$ \\
& $(0.04)$ & $(0.10)$ & {$[0.11]$} & $(0.05)$ & $(0.12)$ & {$[0.22]$} \\
YEN/USD & -0.13 & 1.34 & $\mathbf{0 . 2 3}$ & -0.17 & 1.43 & $\mathbf{0 . 4 0}$ \\
& $(0.12)$ & $(0.26)$ & {$[0.17]$} & $(0.13)$ & $(0.29)$ & {$[0.30]$} \\
GBP/USD & -0.02 & 1.21 & $\mathbf{0 . 2 6}$ & 0.00 & 1.16 & $\mathbf{0 . 4 0}$ \\
& $(0.03)$ & $(0.11)$ & {$[0.19]$} & $(0.04)$ & $(0.13)$ & {$[0.28]$} \\
\hline
\end{tabular}

Note: Estimated parameters of the Mincer-Zarnowitz regression (13), either using the insample forecast of the standard deviation according to the $\operatorname{EGARCH}(1,1)$ model (columns 2-4) or using the SV model with unobserved components (columns 5-7). Robust standard errors are given between parentheses. The adjusted $R^{2}$ 's (à la Andersen et al. 2005), denoted $\bar{R}^{2}$, are reported boldface in columns 4 and 7 while the unadjusted $R^{2}$ 's are reported below between brackets.

and 1 (at the usual 5\% level), respectively for the YEN/USD and GBP/USD series. For the EUR/USD series, both models provide slightly biased estimates of the realized volatility since the $\beta$ 's are significantly higher than 1 . However, there is no doubt about the supremacy of the unobserved components model in terms of predictability of volatility. Indeed, the $\bar{R}^{2}$ 's and $R^{2}$ 's are between $30 \%$ to almost $50 \%$ higher than the ones obtained from the EGARCH $(1,1)$ specification. $^{9}$ Note that the same conclusion applies regardless we use a simple GARCH or a more sophisticated long-memory (E)GARCH model.

\section{Estimating using 3 or 4 currencies}

For the extraction of the currency level and volatility factors three exchange rates, involving 4 currencies, are used as input. In Section 3.2 it was explained how 3 currencies are the bare minimum for extracting the factors, and that adding the fourth can be expected to add extra information and precision in the measurement of the factors. To illustrate the effect, the SV model (without interventions) was estimated both using the 3 currencies (USD, EUR and YEN) and again after adding the British Pound to the mix.

The left panel of Figure 4 displays the average interquartile range (IQR) of the posterior density of the currency level factors of USD, EUR and YEN. Overall, the level factors are estimated more precisely, with a smaller IQR, when a fourth currency is taken into account. This effect is especially strong starting in 1998, when the Asia crisis results in a jump in uncertainty for the Japanese Yen. The information included in the GBP/USD exchange rate is of great worth in that period to get a higher level of precision for the currency factors of the other currencies.

In the right hand panel, the median of the posterior density of the standard deviation of the Euro currency returns is shown. Overall, the estimate of volatility does not differ strongly whether three or four currencies are used. However, especially in the period of stability in

\footnotetext{
${ }^{9}$ Recall from statistics that the unadjusted $R^{2}$ of a simple regression model is the square of the empirical correlation between the endogenous variable and the regressor. For instance for the EUR/USD, $R_{\mathrm{EGARCH}}^{2}=$ $0.11 \approx \operatorname{corr}\left(\mathrm{RV}_{t, i j}, F_{t, i j \mid t-1}^{\mathrm{EGARCH}}\right)^{2}=0.33^{2}$ whereas $R_{\mathrm{SV}}^{2}=0.22 \approx \operatorname{corr}\left(\mathrm{RV}_{t, i j}, F_{t, i j \mid t-1}^{\mathrm{SV}}\right)^{2}=0.47^{2}$
} 

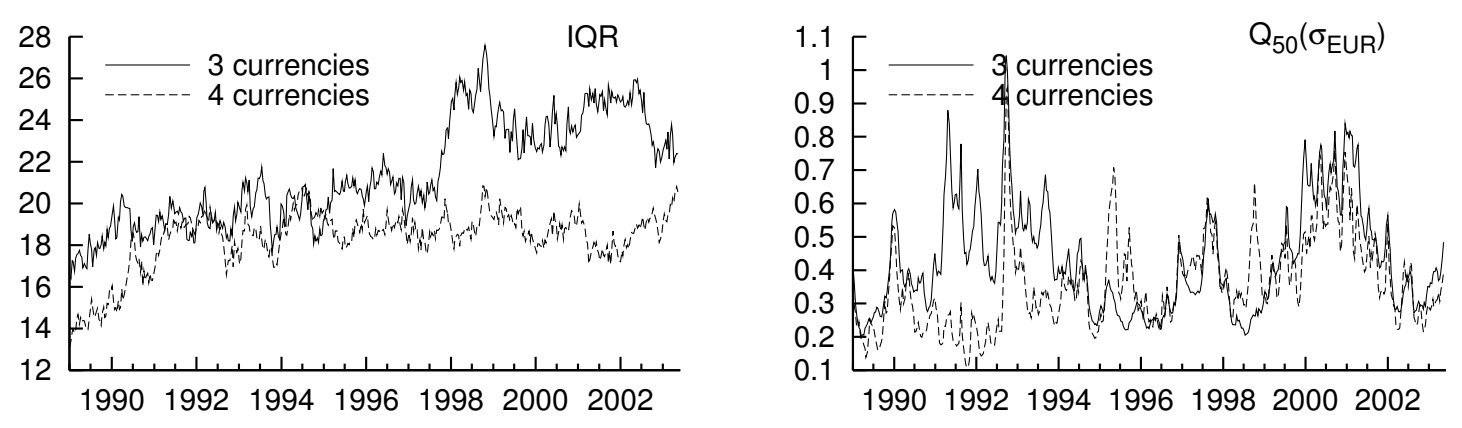

Figure 4: Average interquartile range of the currency level factors (left panel) and the median of the volatility factor $\sigma_{\mathrm{EUR}}$ (right panel) extracted using 3 or 4 currencies, respectively.

the EMS (10/90-9/92), the inclusion of GBP in the estimation indicates that volatility in the EUR/USD exchange rate in this period is not so much due to the EUR as to the USD. Therefore, with four currencies the evaluation of the uncertainty of the EUR is lower than when the GBP left out of the estimation.

\section{Estimation and results}

\subsection{Central bank intervention data}

Our CBIs data capture daily official interventions (as disclosed by the central banks themselves) conducted by the three major central banks over the period from January 11989 to May 31 2003. The CBIs are used as daily signed dummies indicating the purchases or sales of foreign currencies relative to the USD. By convention, the intra-EMS intervention dummy takes a value of 1 for DEM sales, while the one for EUR/YEN interventions is 1 for sales of the Yen.

These data were obtained either through bilateral contacts with the central banks (Fed and European Central Bank) or through downloading the data from the website (Bank of Japan). For these BoJ interventions, due to unavailability of official data before May 1991, the data capture the days of reported interventions for the first part of the sample. Note that the official interventions concerning the British Pound are not available, at least to external researchers; this currency is taken along only in the estimation in order to facilitate the estimation of the currency factors for levels and volatilities.

As usual in the literature, we distinguish between coordinated interventions (operations conducted by the two involved central banks on the same markets, the same day and in the same direction) from unilateral ones. The CBIs are captured by dummy variables as done in most papers of the empirical literature and in a consistent way with the signalling channel which is the underlying theoretical framework used to rationalise the impact of these operations on exchange rates.

We consider eight different types of interventions, with between parentheses the indications that are used in subsequent tables:

- Coordinated operations by the Fed and the ECB (ECB-Fed) on the EUR/USD market;

- Coordinated operations by the Fed and the Bank of Japan (BoJ-Fed) on the YEN/USD 
Table 3: Number of interventions days

\begin{tabular}{ccccc}
\hline \hline & YEN/USD & EUR/USD & EMS & EUR/YEN \\
\hline ECB-Fed & - & 58 & - & - \\
BoJ-Fed & 72 & - & - & - \\
Fed & 31 & 64 & - & - \\
BoJ & 227 & - & - & 18 \\
ECB & - & 33 & - & - \\
BB & - & - & 33 & - \\
\hline
\end{tabular}

Note: The figures report the number of interventions days on each market, over the sample period of $1 / 1 / 1989-31 / 5 / 2003$, by the indicated central banks. The intra-EMS interventions are performed by the Bundesbank, before the ECB was founded in 1998.

market;

- Unilateral operations by the Fed on the EUR/USD market;

- Unilateral operations by the Fed on the YEN/USD market;

- Unilateral operations by the European Central Bank (ECB) on the EUR/USD market;

- Operations conducted by the Bundesbank (BB) against other European currencies in the context of the European Monetary System (EMS) before the introduction of the Euro;

- Unilateral operations by the BoJ on the YEN/USD market;

- Unilateral operations by the BoJ on the EUR/YEN market.

The number of intervention days broken down by type of operation and by currency market is reported in Table 3.

\subsection{Quotation time}

While our analysis is conducted at the daily frequency, we pay particular attention to the choice of the quotation time $Q$ of the exchange rates $S_{t, i j}$. The importance of this choice stems from the recent findings of the literature suggesting that the impact of CBIs on the moments of exchange rate returns can be of short-run duration and mean-reverting (Dominguez 2003 and 2004; Payne and Vitale 2003; Beine et al. 2004). As emphasised by Beine et al. (2004), such evidence stresses the importance of choosing an appropriate and separate quotation time to study the impact of each type of operation. Appendix A discusses in detail the choice of the optimal quotation time relative to each type of operation.

Another approach is to conduct a pure intraday analysis on the impact of CBIs but this is not feasible at present. First, the exact timings of the operations conducted by the three central banks studied here are not available. Secondly, conducting a pure intraday analysis may be cumbersome since intraday FX data are known to exhibit a complex seasonality pattern. This intraday periodicity gives rise to a striking repetitive U-shape pattern in the autocorrelations of the absolute or squared returns, which are proxies for the volatility. While theoretically feasible, extracting both the unobserved country specific volatilities and their 
seasonality using the Bayesian methods developed by Bos and Shephard (2004) is obviously beyond the scope of the paper.

\subsection{EGARCH estimates}

For the sake of comparison, we complement our analysis in terms of country factors by a traditional GARCH analysis aimed at capturing the impact of interventions on the first two moments of the exchange rate returns. As surveyed by Humpage (2003), this type of approach has been extensively used in the empirical literature and might be considered as a useful benchmark to assess the contribution of our analysis. To this aim, we rely on the EGARCH $(1,1)$ specification presented in equations (8)-(11) with CBIs introduced both in the conditional mean and variance equations.

\subsection{Results}

Table 4 reports the estimates of the impact of CBIs. Columns 4-6 (labelled 'EGARCH') give respectively the estimates of the impact of CBIs on the exchange rate moments using the EGARCH approach $\left(\beta^{\dagger}\right.$ and $\gamma^{\dagger}$ parameters), their robust standard errors $(s)$ and the $p$-value for a one-sided test of significance of the parameters $(p)$. Columns 7-10 (labelled 'Bayesian SV') report the posterior mean of the impact of CBIs on the currency components of these exchange rates ( $\beta$ and $\gamma$ parameters), their standard deviation $(s)$ and the $p$-value for a one-sided test of significance of the parameters $(p) .{ }^{10}$ The upper panel (labelled 'Mean equation') reports the findings relative to the mean (first moments on either the exchange rate returns or the country factors) while the lower panel (labelled 'Variance equation') provides the results relative to the volatility side (second moment of either the exchange rate returns or the country factor increments).

For the sake of brevity, we only report the estimates of the impact of each type of operation. It should be nevertheless clear that each estimate comes from the estimation of the full model, i.e. the one admitting a specification in which all components of $W_{t, i j}$ (for the EGARCH model) or $W_{t, i}$ (for SV) are included both in the mean and variance equations. The model is estimated using a quotation time $Q$ for $S_{t, i j}$ corresponding to the likelihood of the occurrence of the investigated operation. This timing is reported in column 3. For instance, the estimates of the impact of coordinated interventions of the Fed and the ECB are reported from the estimation of the models using $S_{t, i j}$ observed at $Q=15 \mathrm{~h} \mathrm{GMT}+1$, as this is the quotation timing around which the interventions are most likely to have taken place. The choice of the optimal quotation time is motivated in Appendix A.

It should be first emphasised that in general, the results obtained in the empirical literature using GARCH models are to a certain extent sample-specific (Humpage 2003). This partly reflects that intervention policies change over time. This explains why our EGARCH results are representative of this literature only to some degree and that there exists some discrepancies with previous studies. The choice of the 'optimal' quotation time, the use of a specific GARCH model and the type of interventions might also explain these discrepancies. ${ }^{11}$

\footnotetext{
${ }^{10}$ The choice for one-sided $p$-values is motivated by the fact that we consider the $p$-value as a test for the significance of the (correct) sign of the parameter.

${ }^{11}$ For instance, using reported interventions of the BoJ before 1991, Beine et al. (2002) find some significant impact of the coordinated interventions on the YEN/USD over the 1985-1995 period.
} 
Table 4: Impact of central bank interventions, 1989-2003

\begin{tabular}{|c|c|c|c|c|c|c|c|c|c|}
\hline \multicolumn{10}{|c|}{ Mean equation } \\
\hline \multirow[b]{2}{*}{$\operatorname{Bank}(\mathrm{s})$} & \multirow[b]{2}{*}{ FX } & \multirow[b]{2}{*}{$Q$} & \multicolumn{3}{|c|}{ EGARCH } & \multicolumn{4}{|c|}{ Bayesian SV } \\
\hline & & & $\beta_{1}^{\dagger}$ & $s$ & $p$ & Cur & $\beta$ & $s$ & $p$ \\
\hline \multirow[t]{2}{*}{ ECB-Fed } & EUR/USD & 15 & -0.138 & 0.161 & 0.20 & USD & 0.100 & 0.113 & 0.19 \\
\hline & & & & & & EUR & 0.023 & 0.042 & 0.29 \\
\hline \multirow[t]{2}{*}{ BoJ-Fed } & YEN/USD & 3 & -0.311 & 0.122 & 0.01 & USD & -0.041 & 0.098 & 0.34 \\
\hline & & & & & & YEN & 0.041 & 0.063 & 0.26 \\
\hline \multirow[t]{2}{*}{ ECB } & EUR/USD & 12 & -0.277 & 0.184 & 0.07 & USD & 0.042 & 0.119 & 0.36 \\
\hline & & & & & & EUR & 0.057 & 0.059 & 0.17 \\
\hline $\mathrm{BB}$ & EMS & 14 & 0.009 & 0.136 & 0.49 & EUR & 0.168 & 0.115 & 0.07 \\
\hline \multirow[t]{2}{*}{ Fed } & EUR/USD & 17 & -0.095 & 0.067 & 0.08 & USD & 0.078 & 0.084 & 0.18 \\
\hline & & & & & & EUR & 0.036 & 0.036 & 0.15 \\
\hline \multirow[t]{2}{*}{ Fed } & YEN/USD & 17 & -0.192 & 0.129 & 0.07 & USD & 0.249 & 0.158 & 0.06 \\
\hline & & & & & & YEN & 0.018 & 0.066 & 0.39 \\
\hline \multirow[t]{2}{*}{ BoJ } & YEN/USD & 3 & -0.279 & 0.060 & 0.00 & USD & 0.002 & 0.035 & 0.48 \\
\hline & & & & & & YEN & -0.017 & 0.041 & 0.34 \\
\hline \multirow[t]{2}{*}{ BoJ } & EUR/YEN & 3 & 0.275 & 0.130 & 0.02 & EUR & -0.222 & 0.141 & 0.06 \\
\hline & & & & & & YEN & 0.151 & 0.189 & 0.21 \\
\hline \multicolumn{10}{|c|}{ Variance equation } \\
\hline \multirow[b]{2}{*}{$\operatorname{Bank}(\mathrm{s})$} & & & \multicolumn{3}{|c|}{ EGARCH } & \multicolumn{4}{|c|}{ Bayesian SV } \\
\hline & FX & $Q$ & $\gamma_{1}^{\dagger}$ & $s$ & $p$ & Cur & $\gamma$ & $s$ & $p$ \\
\hline \multirow[t]{2}{*}{ ECB-Fed } & EUR/USD & 15 & 0.918 & 0.299 & 0.00 & USD & 0.790 & 0.253 & 0.00 \\
\hline & & & & & & EUR & 0.198 & 0.296 & 0.25 \\
\hline \multirow[t]{2}{*}{ BoJ-Fed } & YEN/USD & 3 & 0.444 & 0.056 & 0.00 & USD & 0.412 & 0.237 & 0.04 \\
\hline & & & & & & YEN & 0.962 & 0.236 & 0.00 \\
\hline \multirow[t]{2}{*}{ ECB } & EUR/USD & 12 & 0.098 & 0.122 & 0.40 & USD & 0.382 & 0.319 & 0.12 \\
\hline & & & & & & EUR & 0.463 & 0.339 & 0.09 \\
\hline $\mathrm{BB}$ & EMS & 14 & 0.166 & 0.078 & 0.02 & EUR & 0.774 & 0.365 & 0.02 \\
\hline \multirow[t]{2}{*}{ Fed } & EUR/USD & 17 & -0.040 & 0.043 & 0.17 & USD & 0.603 & 0.249 & 0.01 \\
\hline & & & & & & EUR & -0.381 & 0.384 & 0.16 \\
\hline \multirow[t]{2}{*}{ Fed } & YEN/USD & 17 & -0.170 & 0.122 & 0.09 & USD & 0.530 & 0.347 & 0.06 \\
\hline & & & & & & YEN & -0.048 & 0.361 & 0.45 \\
\hline \multirow[t]{2}{*}{ BoJ } & YEN/USD & 3 & 0.051 & 0.037 & 0.09 & USD & 0.026 & 0.139 & 0.43 \\
\hline & & & & & & YEN & 0.324 & 0.138 & 0.01 \\
\hline \multirow[t]{2}{*}{ BoJ } & EUR/YEN & 3 & -0.220 & 0.124 & 0.04 & EUR & 0.433 & 0.448 & 0.17 \\
\hline & & & & & & YEN & 0.850 & 0.425 & 0.02 \\
\hline
\end{tabular}

Note: The entries report the estimated impact of the corresponding CBIs (see columns 1 and 2), based on the EGARCH model (columns 4-6, using QMLE estimation) and the Bayesian SV model (columns 7-10). The column $Q$ indicates the quotation time of the exchange rate used to estimate the EGARCH of the Bayesian SV models. The columns marked by $s$ and $p$ report the robust standard errors and the $p$-value for a one-sided test of significance of the parameters. 


\subsubsection{Mean results}

If one defines an efficient operation as the one moving the exchange rate in the desired direction, i.e. net purchases of dollars leading to an appreciation of the dollar, an efficient operation implies positive coefficients of CBIs in the mean equation of the EGARCH model (i.e. $\beta_{1}^{\dagger}>0$ ), positive coefficients on the non-US (Euro or Yen) component (i.e. $\beta_{\text {EUR }}>0, \beta_{\text {YEN }}>0$ ) and negative coefficients on the US component (i.e. $\left.\beta_{\mathrm{US}}<0\right) .{ }^{12}$ An important exception concerns the impact of the so-called auxiliary interventions (BB within the EMS, and the BoJ on the EUR/YEN market). Since all exchange rates are expressed in terms of USD, it is impossible to define an expected coefficient in the EGARCH model for these operations. In this sense, the significantly positive coefficient associated to unilateral interventions of the BoJ on the EUR/YEN obtained in the EGARCH specification is difficult to interpret. In contrast, given the definitions of these interventions, efficiency in the factor approach implies a positive coefficient on the Euro component associated to EMS interventions, a negative coefficient on the Euro component associated to interventions on the EUR/YEN and a positive coefficient on the YEN component associated to interventions on the EUR/YEN.

In line with the literature, our EGARCH estimates for the impact on the level of exchange rate returns suggest that CBIs are poorly efficient instruments, at least at a daily frequency. Coefficients relative to the impact of the mean are either insignificant at the $5 \%$ critical level (ECB-Fed:EUR/USD, ECB:EUR/USD, Fed:EUR/USD) or significantly negative (BoJ:YEN/USD, Fed:YEN/USD). Negative coefficients suggest that these operations have delivered some so-called perverse effects, i.e. have moved the exchange rate in the opposite direction with respect to the targeted one. Though several attempts have been made, it is found to be difficult to rationalise these counterintuitive results. ${ }^{13}$ They are furthermore at odds with the recent evidence in favour of efficient operations in the very short run (Dominguez 2003).

Consistent with the findings obtained in the EGARCH approach in particular and by the empirical literature in general, our factor approach also points to poor efficiency of interventions. Nevertheless, we do not find any evidence of counterproductive impact in terms of the currencies. Furthermore, an interesting contribution of our factor approach lies in the estimated impact of the intra-EMS interventions conducted by the Bundesbank. Looking at the impact in terms of the Euro component, the results point to some (weakly) efficient operations of the Bundesbank since in general DEM sales tended to lower the value of the German currency. The same holds for the sales of YEN against the Euro carried out by the BoJ which tended to appreciate the European currency. These results illustrate that auxiliary interventions are easier to interpret in a currency factor model. They show that they turn out to be important control variables to be taken into account in an econometric analysis aimed at capturing the effect of CBIs.

\footnotetext{
${ }^{12}$ As discussed by several authors like Fatum (2002), such a definition of efficiency might be very restrictive in the sense that there is no guarantee that it matches the objective(s) of the central bank. Such a definition nevertheless conveys the advantage of simplicity and delivers a testable proposition.

${ }^{13}$ For instance, Bhattacharya and Weller (1997) model the interaction process between the central bank and market participants in the presence of interventions. They discuss the conditions under which the impact of CBIs might be close to zero or even perverse. This might occur when a central bank puts an important weight on its own exchange rate target compared to the fundamental equilibrium value.
} 


\subsubsection{Volatility results}

The results in terms of volatility in the EGARCH approach illustrate several well-known stylised facts documented in the literature. First, interventions are clearly found to raise rather than to lower exchange rate volatility. This has been extensively documented by numerous authors including the early contributions of Baillie and Osterberg (1997) and Dominguez (1998). Consistent with the previous literature, we find no evidence of negative significant impact, either in terms of exchange rate or in terms of currency component. ${ }^{14}$ Second, in general, coordinated interventions (see ECB-Fed:EUR/USD and BoJ-Fed:YEN/USD operations) are found to exert stronger effects than unilateral operations. This result is consistent with many other previous findings (Catte, Galli and Rebecchini 1992, Beine et al. 2002, among others). It confirms that the impact depends on the information conveyed by those operations as argued by the signalling theory. Nevertheless, results in Table 4 show that unilateral interventions may also exert some weaker direct impact, in line with some previous studies (Dominguez 1998, Beine et al. 2004).

With respect to the volatility side, the factor approach adopted in this paper allows to shed some interesting light on the impact of these interventions. The distinction between currency components allows to identify significant impacts which are not captured in the classical approach in terms of exchange rates. The discrepancy in terms of findings between the two approaches is partly due to the fact that the impact in terms of exchange rates is a non-linear combination of the impacts in terms of currency components.

First, the CBIs are not found to affect the volatility of the USD more than the volatility of the other currencies involved in the FX operation. In this respect, the results are not supportive of the existence of any USD-bias in the investigation of CBIs and suggest a negative answer to Question 2 concerning the existence of a specific dollar effect.

Second, the results of the factor approach allow to document interesting asymmetric effects of CBIs in terms of volatility. The results in Table 4 suggest that unilateral interventions tend to exert highly asymmetric effects in terms of the volatility of the currencies. It is found that unilateral CBIs tend to impact the volatility of the currency of the central bank conducting the intervention. For instance, a unilateral intervention conducted by the Fed tends to primarily impact the uncertainty of the US currency (see the coefficients of the Fed:EUR/USD and Fed:YEN/USD). Strikingly, the same result holds for the BoJ on the YEN/USD as well for the ECB on EUR/USD. These results question the usual conclusion of the empirical literature emphasizing the absence of any impact of unilateral interventions. They suggest that operations of this type not only fail to deliver the desired effect in terms of level of the currency but also involve some significant costs in terms of uncertainty. ${ }^{15}$ Interestingly, this contrasts with the impact associated to concerted operations. The coordinated interventions between the Fed and the BoJ are indeed found to affect the volatility of both currency components. Such evidence is less obvious for the coordinated interventions between the Fed and the ECB. On the whole, these results are also clearly supportive of an operating signalling channel for the FOREX interventions in the sense that the operations mostly affect the expectations of agents regarding the currency of the central bank present in the market and not the other currency component. Our results suggest that depending on the type of

\footnotetext{
${ }^{14}$ Once again, the coefficient obtained in the EGARCH specification for the EUR/YEN interventions is difficult to interpret.

${ }^{15}$ Once more, we implicitly adopt here the usual view that central banks tend to dislike bursts of volatility of their currencies. This view has nevertheless been scarcely questioned by a couple of authors (e.g. Hung 1997).
} 
operation, interventions induce different impacts on the currency market, at least in terms of volatility. The existence of general asymmetric effects of concerted and unilateral operations is broadly speaking consistent with previous evidence. ${ }^{16}$ Hence, the answer to Question 1, on the evidence of asymmetric effects between unilateral and concerted operations, is obviously affirmative.

Another interesting insight concerns the impact of auxiliary interventions. Unlike the approach in terms of exchange rates, the decomposition in currency factors succeeds in capturing volatility effects of these interventions. The rationale for this result might be the following. Referring to the signalling channel which has by far received the most important empirical support, there is no theoretical reason why we should expect some intra-EMS interventions or interventions on the DEM/YEN market to impact the volatility of the USD. As a result, the variation of the exchange rate expressed in USD is likely to be smoothed, in comparison with the variation of the EUR or YEN components. In contrast, the identification of the currency component allows to abstract from this drawback and permits a clear identification of the increase of the volatility. These results imply that auxiliary interventions tend to have some indirect impact on the exchange rate and could be considered as relevant control variables in future investigations of the impact of CBIs. In this sense, they lead to a positive answer to Question 3.

\section{Conclusion}

In this paper, we assess the impact of foreign exchange interventions carried out by the G-3 central banks over the recent period. Unlike the traditional approaches in terms of exchange rates, we propose to investigate the impact of these operations on the first two moments of the currency components of these exchange rates. The identification of these components is carried out through the estimation of a recent Bayesian stochastic volatility model proposed by Bos and Shephard (2004) augmented by explanatory variables both in the mean and the volatility parts. Through the analysis of the effects of the central bank interventions, our paper provides a first attempt to capture asymmetric effects of financial news in the foreign exchange markets in terms of currencies.

Our results provide new insights on the impact of these interventions. First, they confirm that in general, central bank operations do not succeed in moving the exchange rate in the desired directions and tend to lead to more uncertainty. Nevertheless, our results in terms of currency dynamics are not, in contrast with some previous empirical studies based on more traditional approaches, supportive of perverse effects associated to these operations. Second, our results do not support the existence of some USD bias in the sense that the US currency would be impacted more by direct purchases or sales performed by the major central banks. Third and importantly, while the traditional approaches do not identify clear effects in terms of exchange rate volatility, we find that unilateral interventions obviously tend to primarily raise the volatility of the currency of the central bank involved in these operations. This contrasts with the effect associated with concerted operations and might be considered as some additional evidence in favour of the signalling channel hypothesis for the effect of interventions. Finally, our approach allows to capture in a more rational way the impact of

\footnotetext{
${ }^{16}$ See for instance Beine, Laurent and Lecourt (2003) showing that depending on the level of volatility, the concerted interventions might deliver positive or negative impact. Such an effect does not hold for unilateral operations.
} 
operations carried out by the central banks on other, possibly indirectly related, markets.

This paper can be extended to a full intra-day analysis. Such an analysis however should overcome the fact that exact timings of official interventions are not available. This could be done by relying on the timings extracted from the newswire reports as proposed by Dominguez (2004). Another hurdle concerns the application of the estimation techniques to high-frequency data as well as the way to account for intra-daily seasonality patterns and for the occurrence of microstructure noise induced by the high frequency. These extensions are left for future research. 


\section{A Timing of CBIs}

As explained in Section 4.2, the choice of the quotation time of the exchange rate is of primary importance for assessing the impact of CBIs on the dynamics of exchange rates and currency components. In this appendix, we discuss for each type of operation the choice of the optimal quotation time, i.e. the quotation time necessary to capture, if any, the potential impact of these operations. Basically, we can rely on a set of elements which, together, suggest a likely time range:

- The opening hours of the local markets. As documented by Dominguez (1998, 2003), most central banks tend to operate on their own local markets, providing orders to the domestic commercial banks;

- The need to coordinate with another central bank, for concerted operations;

- The empirical distribution of the timings of reported interventions for each central bank (Dominguez 1999).

The empirical distributions involve the timing of the interventions perceived by the FX traders using Reuters' newswire reports. They nevertheless ignore the secret, unreported interventions, which according to Dominguez (2003) may account for up to $25 \%$ of the Fed interventions over the 1989-1995 period. They also do not account for the possible lags between the effective operations and the trader reports. Recent results obtained by Payne and Vitale (2003) show that exchange rates react up to 45 minutes ahead of Reuters' intervention reports on operations of the Fed. Importantly, the lengths of these lags may be variable as the reporting depends on the dealers' willingness to release the information.

The moments of these distributions, together with information on the opening hours of the local markets of the intervening banks, nevertheless provide useful insight in the possible timing of the operations.

\section{A.1 Coordinated interventions on the EUR/USD}

Following the discussions in Dominguez $(1998,2003)$ as well as the evidence of Beine et al. (2004) with respect to impact of CBIs on volatility, we assume that the coordinated interventions of the Fed and the ECB take place during the overlap period (ranging between $13 \mathrm{~h}$

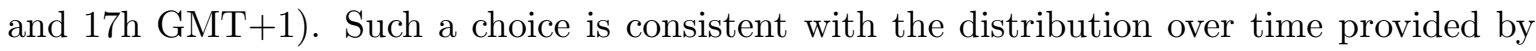
Dominguez (1999) using Reuters reports. We therefore pick up the middle of the time range for the exchange rate quotation, i.e. $15 \mathrm{~h} \mathrm{GMT}+1$. This choice is consistent with the evidence provided by Beine et al. (2004).

\section{A.2 Coordinated interventions on the YEN/USD}

Unlike coordinated interventions between the ECB and the Fed, there is no overlap period between the Japanese and the US market. Therefore, assuming that most interventions are carried out by central banks on their own local markets (see Dominguez 1999, on this particular point), a coordinated intervention on this market takes the form of an intervention of the BoJ followed by an intervention of the Fed. An initial BoJ intervention will therefore induce some reaction of the markets during Japanese trading time. We therefore investigate the impact using the middle of the time range for the exchange rate quotation, i.e. at $3 \mathrm{~h}$ GMT+1. 


\section{A.3 Unilateral interventions of the ECB on the EUR/USD}

When carrying out a unilateral operation, the ECB (or Bundesbank) does not need to take advantage of the simultaneous opening of the US and the European market. Therefore, the operation can take place either before or after the opening of the US market (13h GMT+1). Such a procedure is consistent with the evidence provided by Dominguez (1999) documenting an average time of occurrence of ECB operations around 12h30 GMT +1 . We therefore use the quotation at $12 \mathrm{~h} \mathrm{GMT}+1$.

\section{A.4 Intra-EMS interventions of the BB affecting the EUR/USD}

All EMS interventions are coordinated interventions in the sense that they involve the same operation on the part of the BB and other European central banks. Notice that we do not have the counterpart EMS currency against which the German Mark was traded, and therefore do not know which second European central bank was involved in these operations. Given the fact that these operations can occur all over the day, we choose $14 \mathrm{~h}$ GMT +1 as our exchange rate quotation.

\section{A.5 Unilateral interventions of the Fed on the EUR/USD and the YEN/USD}

When carrying out a unilateral operation, the Fed does not need to take advantage of the simultaneous opening of the US and the European market. Therefore, the operation can take place either before of after the close of the European market (17h GMT+1). Such a procedure is consistent with the evidence provided by Dominguez (1999) documenting an average time of occurrence of Fed operations around 15h57 GMT+1. The distribution over time (Figure 2 in the article mentioned) shows a significant part of the operations occurring after $16 \mathrm{~h} \mathrm{GMT}+1$. The same line of reasoning can apply to the unilateral interventions of the Fed on the YEN/USD market. Hence we use the quotation 17h GMT +1 to assure that the intervention actually took place before the measurement of the exchange rate.

\section{A.6 Unilateral interventions of the BoJ on the YEN/USD and the EU/YEN}

Given the stylised fact that most central banks use a network of domestic commercial banks to carry out their interventions, it might be inferred that the vast majority of BoJ interventions are carried out between $0 \mathrm{~h}$ and $7 \mathrm{~h}$ GMT +1 . This is confirmed by the evidence given by Dominguez (1999), with an average BoJ intervention time around Tokyo lunchtime, with a mean at $4 \mathrm{~h} 56 \mathrm{GMT}+1$. Like for the coordinated interventions, we choose $3 \mathrm{~h}$ GMT +1 as our quotation time. 


\section{B Statistical background}

The currency factor-stochastic volatility model presented in Section 3 is built up from unobserved components $e_{t, i}$ for the level and $h_{t, i}$ for the volatility of the exchange rates. For ease of reference, the model was written as

$$
\begin{aligned}
s_{t, i j} & =e_{t, i}-e_{t, j}, & & i, j=0, \ldots, n, \\
e_{t+1, i} & =\beta_{t, i}+e_{t, i}+\epsilon_{t, i}, & \epsilon_{t, i} & \sim \mathcal{N}\left(0, \exp \left(h_{t, i}\right)\right), \\
h_{t+1, i}-\gamma_{t+1, i} & =\phi_{i}\left(h_{t, i}-\gamma_{t, i}\right)+\xi_{t, i}, & & \xi_{t, i} \sim \mathcal{N}\left(0, \sigma_{\xi, i}^{2}\right),
\end{aligned}
$$

with $\beta_{t, i}$ and $\gamma_{t, i}$ including the regression effects of the interventions, and $t=0, \ldots, T$.

The country factors are initialised at $e_{0,0} \equiv 0$ for the numeraire country, and all other factors $e_{0, i} \equiv s_{0, i 0}, i \neq 0$ at the respective log-exchange rate. The volatility sequences are initialised diffusely, with $h_{0, j} \sim \mathcal{N}\left(\gamma_{0, j}, \kappa\right), \kappa \rightarrow \infty, j=0, \ldots, n$. As long as there are at least 3 countries involved, this model is identified with these initialisations.

The relation between (log-) exchange rates $s_{t, i j}$ and the respective volatilities $h_{t, i}, h_{t, j}$ is clearly non-linear. In such a case, convenient classical estimation methods are not available. Therefore, we apply a Bayesian estimation procedure to this model (see Doucet, de Freitas and Gordon 2001, for an introduction to Markov chain Monte Carlo sampling techniques), using a sampling scheme for stochastic volatility models which was developed originally in papers like Harvey et al. (1994) and Jacquier et al. (1994), and further refined for the case of multiple SV sequences on longer time horizons by Bos and Shephard (2004).

In this last paper, a Bayesian sampling procedure is proposed for models with stochastic volatility and a conditionally Gaussian State Space form (GSSF-SV). The variant of the algorithm applied here samples from the augmented parameter space consisting of $\theta=$ $\left(\sigma_{\xi}, \phi, \gamma, \beta\right)$ and unobserved components $\mathbf{e}=\left\{e_{t, i}, t=0, \ldots, T, i=0, \ldots, n\right\}$ and $\mathbf{h}=\left\{h_{t, i}, t=\right.$ $0, \ldots, T, i=0, n\}$. It applies a transformation from the volatility sequence $h_{i}$ to the standardised disturbances $u_{t, i} \equiv \xi_{t, i} / \sigma_{\xi, i}=f^{-1}\left(\mathbf{h}, \sigma_{\xi}, \phi, \gamma\right)$ of the volatility processes, as this improves the convergence of the sampling algorithm greatly.

The sampling procedure follows a Gibbs sampling scheme, where the parameters are sampled in blocks, conditional on all other parameters of the model. This sampling density, the full conditional posterior density, is constructed as a combination of the likelihood of the model and the prior density of the parameters; based on earlier experience with similar models the priors as specified in Table 5 are chosen. These priors are chosen to be only mildly informative, such as to assure existence of all conditional posterior densities, but allow the information in the likelihood to determine the location and shape of the posterior density.

Table 5: Prior specifications

\begin{tabular}{llcc} 
Parameter & Density & Expectation & Standard deviation \\
\hline$\sigma_{\xi, i}$ & Inverted Gamma & 0.2 & 0.2 \\
$\phi_{i}$ & Beta & 0.86 & 0.1 \\
$\gamma, \beta$ & Normal & 0 & 2 \\
\hline \hline
\end{tabular}

With these preliminaries settled, the final algorithm applies the following steps:

1. Initialise $\mathbf{u}, \theta$, and compute $\mathbf{h}=f\left(\mathbf{u}, \sigma_{\xi}, \phi, \gamma\right)$ as a function of $\mathbf{u}$.

2. Update draw from $\theta, \mathbf{e} \mid \mathbf{s}, \mathbf{u}$ by 
(a) Sampling from $\theta \mid \mathbf{s}, \mathbf{u}$;

(b) Sampling from $\mathbf{e} \mid \mathbf{s}, \mathbf{h}\left(\mathbf{u}, \sigma_{\xi}, \phi, \gamma\right), \theta$ using the generic GSSF simulation smoother (Frühwirth-Schnatter 1994, Carter and Kohn 1994, De Jong and Shephard 1995, Durbin and Koopman 2002).

3. Recompute $\mathbf{h}$ from $\mathbf{u}$ and $\theta$, sample from $\mathbf{h} \mid \mathbf{e}, \mathbf{s}, \theta$, and reconstruct $\mathbf{u}=f^{-1}\left(\mathbf{h}, \sigma_{\xi}, \phi, \gamma\right)$. The sampling is performed using the method in Kim, Shephard and Chib (1998), sampling effectively $h_{t} \mid h_{t-1}, h_{t+1}, \theta, \mathbf{s}$, for $t=1, \ldots, T$.

4. Repeat from 2.

Bos and Shephard (2004) discuss a range of possibilities for step 2a. In this paper we use a number of measures to increase the speed of convergence of the algorithm:

- The level intervention parameters $\beta$ are taken up into the state using an augmented state vector (see Durbin and Koopman 2001). In this manner, the posterior density of the $\beta$ 's follows without any additional sampling (at the cost of a larger state vector).

- Parameters of the volatility equations are sampled separately per country. As the persistence of volatility in the U.S. is purportedly not related to the persistence in the Euro area, i.e. the parameters can be supposed largely independent, sampling can be done separately without introducing extra correlation in the chain of draws from the parameter space.

- The level of the volatility, governed by $\gamma_{i}$, is sampled from its full conditional density $\left(\gamma_{i} \mid \phi_{i}, \sigma_{\xi, i}, \mathbf{u}_{i}\right)$. This density can be approximated by a multivariate normal density, with mean and variance closely related to a convolution of Gumbel Extreme Value densities.

- The remaining parameters, $\phi_{i}$ and $\sigma_{\xi, i}$ are sampled using a random walk Metropolis algorithm, see Chib and Greenberg (1995).

This sampling scheme delivers draws from the posterior density of the parameters in $\theta$ and of the unobserved components $e_{t}, h_{t}$. Note that all the sampled values are based on all exchange rates, over the full time period. In terms of the state space model, the samples correspond to 'smoothed' estimates, instead of filtered estimates. In case full filtered estimates are requested, a particle filter is be used (Pitt and Shephard 1999).

\section{Posterior sampling}

Using the method exposed in Appendix $\mathrm{B}$, a collection of the parameters $\sigma_{\xi}, \phi, \gamma, \beta$ (and factors $\mathbf{e}$ and $\mathbf{h}$ ) is sampled from the posterior density. While the main interest lies in the sampled factors, the model parameters $\sigma_{\xi}, \phi, \gamma, \beta$ play their own role in modelling persistence of the stochastic volatility, and the size of the influence of each type of the CBIs.

For the results on the extracted factors themselves, in Section 3.4, Figures 2-3 and the Mincer-Zarnowitz regressions of Table 2, a sample of size 100,000 was collected, after a burn-in period of 20,000 iterations. This sample did not include any interventions, the only parameters in the model are the ones governing the stochastic volatility processes of the factors.

Table 6 displays the posterior mean, the standard deviation, the range from the $2.5 \%$ to the $97.5 \%$ quantile, the autocorrelation at lag 30 and the inefficiency measure as highlighted 
in Shephard and Pitt (1997). The inefficiency measure indicates the amount of correlation in the chain, comparing the variation of the parameter to a measure of variation adapted for the autocorrelation at a window of the size of 2,000 lags. A theoretical value of 1 would indicate a fully efficient sample with independent drawings, whereas high values are a sign of higher correlation in the chain and hence lower efficiency of the sampling method.

Table 6: Posterior statistics for the factor SV model

\begin{tabular}{lccrrrr} 
Parameter & Factor & Mean & Std. dev & {$\left[Q_{2.5 \%}, Q_{97.5 \%}\right]$} & $\rho_{30}$ & Ineff \\
\hline$\sigma_{\xi}$ & USD & 0.152 & 0.02 & {$[0.11,0.20]$} & 0.59 & 218.6 \\
& EUR & 0.185 & 0.03 & {$[0.14,0.24]$} & 0.55 & 213.6 \\
& YEN & 0.237 & 0.03 & {$[0.18,0.30]$} & 0.47 & 118.9 \\
$\phi$ & GBP & 0.336 & 0.05 & {$[0.24,0.45]$} & 0.61 & 251.1 \\
& & & & & & \\
& USD & 0.981 & 0.01 & {$[0.97,0.99]$} & 0.80 & 375.4 \\
& EUR & 0.977 & 0.01 & {$[0.96,0.99]$} & 0.87 & 456.4 \\
$\gamma_{0}$ & YEN & 0.961 & 0.01 & {$[0.94,0.98]$} & 0.71 & 204.4 \\
& GBP & 0.973 & 0.01 & {$[0.95,0.99]$} & 0.83 & 372.8 \\
& USD & -1.689 & 0.14 & {$[-1.92,-1.38]$} & 0.89 & 490.8 \\
& EUR & -2.210 & 0.12 & {$[-2.45,-1.98]$} & 0.81 & 340.0 \\
& YEN & -1.321 & 0.10 & {$[-1.53,-1.12]$} & 0.70 & 196.6 \\
\hline \hline
\end{tabular}

Note: The table reports the posterior mean, standard deviation, 2.5 and $97.5 \%$ quantile, the 30th order autocorrelation and the inefficiency measure (Shephard and Pitt 1997), for the parameters governing the variability, autocorrelation and overall level of the stochastic volatility.

The results of the table suggest that the posteriors of $\sigma_{\xi}$ and $\phi$ are little spread out, and also the posteriors of the $\gamma_{0}$ parameters governing the overall level of volatility are estimated clearly away from the prior mean (see Table 5 for the prior specifications), hence the data is informative on these parameters. This effect is more easily seen in Figure 5, where the prior and posterior densities are drawn together.

Though the data is informative on the parameters, the posterior sample correlation remains high, even after applying the methods of Bos and Shephard (2004). On the other hand, the correlation was low enough for convergence to take place, and the sample at hand is large enough for the analysis in aforementioned sections.

For measuring the impact of central bank interventions, in Table 4, a different timing of the exchange rates was chosen for each of the intervention parameters. Tables 7-8 display the series of statistics for the intervention parameters. The timing of the quotations $Q$ used in the estimation is the same as the one used in the core analysis (see Table 4 in Section 4.4). From these statistics it is once again apparent that the data is informative about the parameters, as the posterior distribution moves away from the prior (see Appendix B; for the intervention parameters the prior is $\pi(\beta, \gamma) \sim \mathcal{N}(0,4))$. The efficiency of sampling these intervention parameters is far higher, hence a sample of size 10,000, with burn-in of 2,000 iterations, was deemed sufficient for the analysis in Section 4 and most notably Table 4 . Using a larger sample size was not possible, due to the high computational burden of models of this type. 

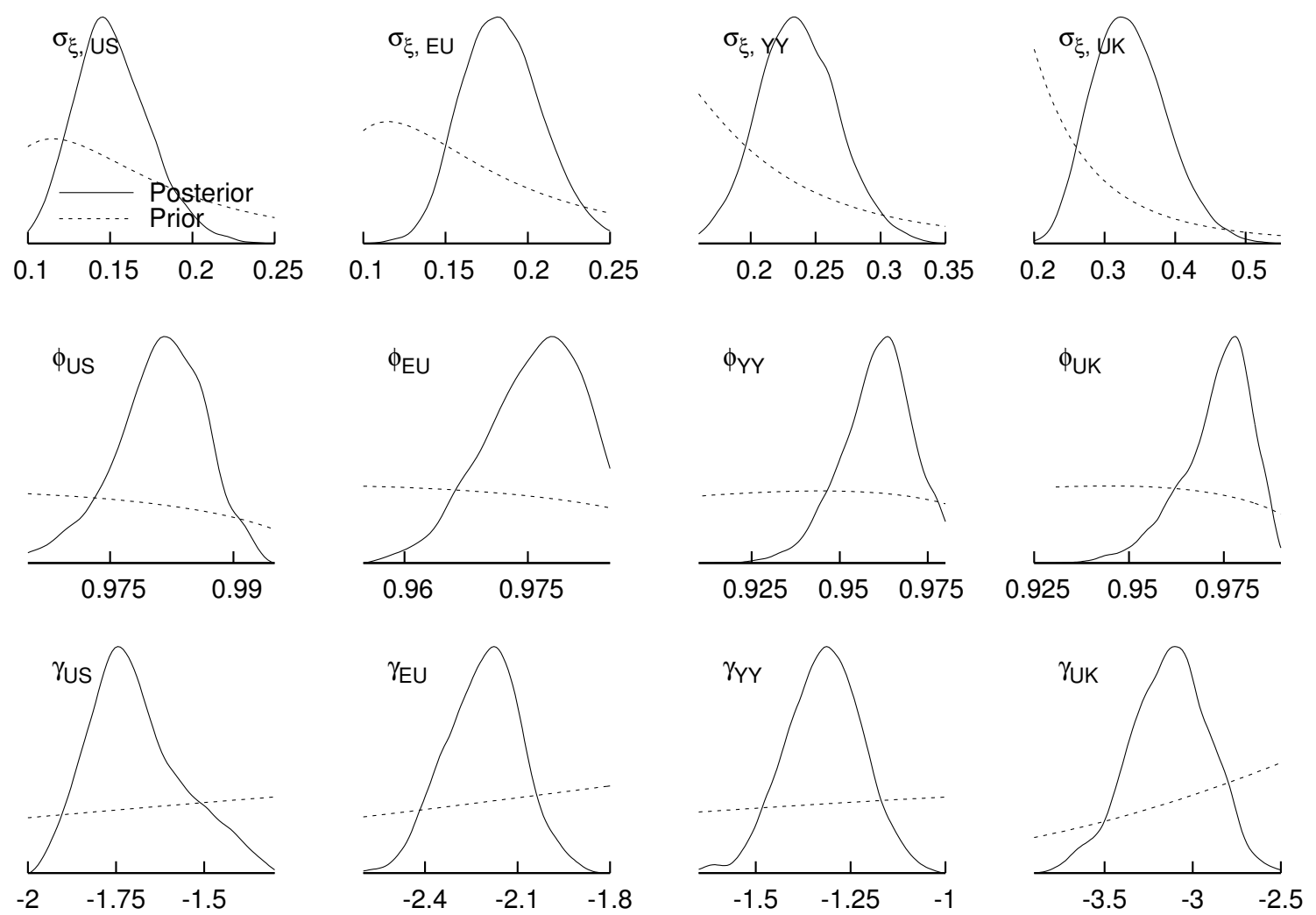

Figure 5: Posterior distribution of parameters of the factor SV model, without interventions, at quotation time $16 \mathrm{~h} \mathrm{GMT}+1$ 
Table 7: Posterior moments of the level intervention parameters $\beta$

\begin{tabular}{lllrrrrrr} 
Banks & FX & Factor & $Q$ & Mean & Std. dev & {$\left[Q_{2.5 \%}, Q_{97.5 \%}\right]$} & $\rho_{30}$ & Ineff \\
\hline ECB-Fed & EUR/USD & USD & 15 & 0.100 & 0.11 & {$[-0.12,0.32]$} & 0.03 & 3.0 \\
ECB-Fed & EUR/USD & EUR & 15 & 0.023 & 0.04 & {$[-0.06,0.11]$} & 0.04 & 7.1 \\
BoJ-Fed & YEN/USD & USD & 3 & -0.041 & 0.10 & {$[-0.23,0.15]$} & 0.05 & -8.0 \\
BoJ-Fed & YEN/USD & YEN & 3 & 0.041 & 0.06 & {$[-0.08,0.17]$} & 0.03 & 6.7 \\
ECB & EUR/USD & USD & 12 & 0.042 & 0.12 & {$[-0.19,0.27]$} & 0.03 & 45.2 \\
ECB & EUR/USD & EUR & 12 & 0.057 & 0.06 & {$[-0.06,0.17]$} & 0.03 & 5.7 \\
ECB & EMS & EUR & 14 & 0.168 & 0.11 & {$[-0.06,0.40]$} & 0.04 & 12.9 \\
Fed & EUR/USD & USD & 17 & 0.078 & 0.08 & {$[-0.08,0.24]$} & 0.04 & 7.7 \\
Fed & EUR/USD & EUR & 17 & 0.036 & 0.04 & {$[-0.03,0.11]$} & 0.03 & 4.8 \\
Fed & YEN/USD & USD & 17 & 0.249 & 0.16 & {$[-0.06,0.56]$} & 0.05 & 3.4 \\
Fed & YEN/USD & YEN & 17 & 0.018 & 0.07 & {$[-0.11,0.15]$} & 0.01 & 6.3 \\
BoJ & YEN/USD & USD & 3 & 0.002 & 0.03 & {$[-0.07,0.07]$} & 0.05 & 29.9 \\
BoJ & YEN/USD & YEN & 3 & -0.017 & 0.04 & {$[-0.10,0.06]$} & $0.06-1.9$ \\
BoJ & EUR/YEN & EUR & 3 & -0.222 & 0.14 & {$[-0.51,0.06]$} & 0.02 & 0.6 \\
BoJ & EUR/YEN & YEN & 3 & 0.151 & 0.19 & {$[-0.21,0.53]$} & 0.05 & 23.3 \\
\hline \hline
\end{tabular}

Note: See Table 4 for a description of the entries; these parameters concern interventions on the level intervention parameters $\beta$, of mentioned banks operating on the exchange rate market in column 2, measuring the effect on the currency in column 3. The parameters are sampled using the timing as in Table 4.

Table 8: Posterior moments of the volatility intervention parameters $\gamma$

\begin{tabular}{|c|c|c|c|c|c|c|c|}
\hline Banks & $\mathrm{FX}$ & Factor & $Q$ & Mean & Std. dev & {$\left[Q_{2.5 \%}, Q_{97.5 \%}\right]$} & $\rho_{30} \quad$ Ineff \\
\hline ECB-Fed & EUR/USD & USD & 15 & 0.790 & 0.25 & {$[0.30,1.30]$} & 0.1331 .1 \\
\hline ECB-Fed & EUR/USD & EUR & 15 & 0.198 & 0.30 & {$[-0.38,0.79]$} & 0.1868 .8 \\
\hline BoJ-Fed & YEN/USD & USD & 3 & 0.412 & 0.24 & {$[-0.05,0.88]$} & 0.1027 .9 \\
\hline BoJ-Fed & YEN/USD & YEN & 3 & 0.962 & 0.24 & {$[0.50,1.44]$} & 0.2070 .0 \\
\hline ECB & EUR/USD & USD & 12 & 0.382 & 0.32 & {$[-0.24,1.02]$} & 0.1193 .4 \\
\hline ECB & EUR/USD & EUR & 12 & 0.463 & 0.34 & {$[-0.19,1.14]$} & 0.1224 .4 \\
\hline ECB & EMS & EUR & 14 & 0.774 & 0.37 & {$[0.07,1.49]$} & 0.1449 .6 \\
\hline Fed & EUR/USD & USD & 17 & 0.603 & 0.25 & {$[0.11,1.09]$} & 0.1982 .4 \\
\hline Fed & EUR/USD & EUR & 17 & -0.381 & 0.38 & {$[-1.17,0.33]$} & 0.1933 .9 \\
\hline Fed & YEN/USD & USD & 17 & 0.530 & 0.35 & {$[-0.16,1.22]$} & 0.1529 .6 \\
\hline Fed & YEN/USD & YEN & 17 & -0.048 & 0.36 & {$[-0.75,0.67]$} & $0.09 \quad 1.2$ \\
\hline BoJ & YEN/USD & USD & 3 & 0.026 & 0.14 & {$[-0.24,0.30]$} & 0.2346 .5 \\
\hline BoJ & YEN/USD & YEN & 3 & 0.324 & 0.14 & {$[0.05,0.59]$} & 0.1646 .8 \\
\hline BoJ & EUR/YEN & EUR & 3 & 0.433 & 0.45 & {$[-0.45,1.31]$} & $0.14-7.0$ \\
\hline BoJ & EUR/YEN & YEN & 3 & 0.850 & 0.43 & {$[0.03,1.71]$} & 0.0618 .9 \\
\hline
\end{tabular}

Note: See Table 7 for a description of the entries. 


\section{References}

Andersen, T. G. and Bollerslev, T. (1998), 'Answering the skeptics: Yes, standard volatility models do provide accurate forecasts', International Economic Review 39, 885-905.

Andersen, T. G., Bollerslev, T. and Meddahi, N. (2005), 'Correcting the errors: Volatility forecast evaluation using high-frequency data and realized volatilities', Econometrica 73, 279-296.

Baillie, R. T. and Osterberg, W. P. (1997), 'Why do central banks intervene?', Journal of International Money and Finance 16(6), 909-919.

Barndorff-Nielsen, O. and Shephard, N. (2002), 'Econometric analysis of realized volatility and its use in estimating stochastic volatility models', Journal of the Royal Statistical Society, B 63, 167-207.

Beine, M. (2004), 'Conditional covariances and direct central bank interventions in the foreign exchange markets', Journal of Banking \& Finance 28, 1385-1411.

Beine, M., Bénassy-Quéré, A. and Lecourt, C. (2002), 'Central bank interventions and foreign exchange rates: New evidence from FIGARCH estimations', Journal of International Money and Finance 21, 115-144.

Beine, M., Laurent, S. and Lecourt, C. (2003), 'Central bank interventions and exchange rate volatility: Evidence from a switching regime analysis', European Economic Review 47(5), 891-911.

Beine, M., Laurent, S. and Palm, F. C. (2004), Central Bank forex interventions assessed using realized moments, Core Discussion Paper 2004/1, UCL, Louvain-la-Neuve.

Beine, M. and Lecourt, C. (2004), 'Secret and reported interventions in the fx market', Finance Research Letters 1(4), 215-225.

Bhattacharya, U. and Weller, P. (1997), 'The advantage to hiding one's hand: Speculation and central bank inyervention in the foreign exchange market', Journal of Monetary Economics 39, 251-277.

Bonser-Neal, C. and Tanner, G. (1996), 'Central bank intervention and the volatility of foreign exchange rates: Evidence from the options market', Journal of International Money and Finance 15(6), 853-878.

Bos, C. S., Mahieu, R. J. and Van Dijk, H. K. (2000), 'Daily exchange rate behaviour and hedging of currency risk', Journal of Applied Econometrics 15, 671-696.

Bos, C. S. and Shephard, N. (2004), Inference for adaptive time series models: Stochastic volatility and conditionally Gaussian state space form, Discussion paper TI 04-015/4, Tinbergen Institute.

Carnero, M. A., Peña, D. and Ruiz, E. (2001), Is stochastic volatility more flexible than GARCH?, Statistics and Econometrics Series WP 01-08, Universidad Carlos III de Madrid. 
Carter, C. K. and Kohn, R. (1994), 'On Gibbs sampling for state space models', Biometrika 81, 541-553.

Catte, P., Galli, G. and Rebecchini, S. (1992), Exchange markets can be managed! report on the G-7. International Economic Insights.

Chib, S. and Greenberg, E. (1995), 'Understanding the Metropolis-Hastings algorithm', The American Statistician 49, 327-335.

De Jong, P. and Shephard, N. (1995), 'The simulation smoother for time series models', Biometrika 82, 339-350.

Detken, C. and Hartman, P. (2000), The euro and international capital markets. ECB Working paper nr. 19

Dominguez, K. (2003), 'The market microstructure of central bank intervention', Journal of International Economics 59, 25-45.

Dominguez, K. M. (1998), 'Central bank intervention and exchange rate volatility', Journal of International Money and Finance 17, 161-190.

Dominguez, K. M. (1999), The market microstructure of central bank intervention. NBER Working Paper no. 7337.

Dominguez, K. M. (2004), When do central bank interventions influence intra-daily and longterm exchange rate movements. Forthcoming in Journal of International Money and Finance.

Doornik, J. A. (2001), Object-Oriented Matrix Programming using Ox, Timberlake Consultants Ltd, London. See http://www.doornik.com/.

Doucet, A., de Freitas, N. and Gordon, N. (2001), Sequential Monte Carlo Methods in Practice, Springer-Verlag, New York.

Durbin, J. and Koopman, S. J. (2001), Time Series Analysis by State Space Methods, Oxford University Press, Oxford.

Durbin, J. and Koopman, S. J. (2002), 'A simple and efficient simulation smoother for state space time series analysis', Biometrika 89, 603-615.

Evans, M. D. D. and Lyons, R. K. (2001), Portfolio balance, price impact, and secret intervention, Working paper 8356, NBER. Forthcoming in Financial Market Structure and Dynamics, Bank of Canada.

Fatum, R. (2002), 'Post-plaza intervention in the DEM/USD exchange rate', The Canadian Journal of Economics 35, 556-567.

Frenkel, J. (1976), 'A monetary approach of the exchange rate: Doctrinal aspects and empirical evidence', Scandinavian Journal of Economics 78, 200-224.

Frühwirth-Schnatter, S. (1994), 'Data augmentation and dynamic linear models', Journal of Time Series Analysis 15, 183-202. 
Harvey, A. C. (1989), Forecasting, Structural Time Series Models and the Kalman Filter, Cambridge University Press, Cambridge.

Harvey, A. C., Ruiz, E. and Shephard, N. (1994), 'Multivariate stochastic variance models', Review of Economic Studies 61, 247-264.

Humpage, O. F. (2003), Government intervention in the foreign exchange market, Working paper 315, Federal Reserve Bank of Cleveland.

Hung, J. (1997), 'Intervention strategies and exchange rate volatility: a noise trading perspective', Journal of International Money and Finance 16, 779-793.

Jacquier, E., Polson, N. G. and Rossi, P. E. (1994), 'Bayesian analysis of stochastic volatility models', Journal of Business \& Economic Statistics 12, 371-417.

Kim, S., Shephard, N. and Chib, S. (1998), 'Stochastic volatility: Likelihood inference and comparison with ARCH models', Review of Economic Studies 64, 361-393.

Koopman, S. J., Shephard, N. and Doornik, J. A. (1999), 'Statistical algorithms for models in state space using SsfPack 2.2', Econometrics Journal 2, 107-160.

Laurent, S. and Peters, J.-P. (2005), G@RCH 4.0, Estimating and Forecasting ARCH Models, Timberlake Consultants.

Mahieu, R. J. and Schotman, P. C. (1994), 'Neglected common factors in exchange rate volatility', Journal of Empirical Finance 1, 279-311.

Mincer, J. and Zarnowitz, V. (1969), The Evaluation of Economic Forecasts, Economic Forecasts and Expectations, in J. Mincer, New York: National Bureau of Economic Research.

Mussa, M. (1981), The role of official intervention. Group of Thirty Occasional Papers no. 6, Group of Thirty, New York.

Nelson, D. B. (1991), 'Conditional heteroskedasticity in asset returns: A new approach', Econometrica 59, 349-370.

Pagan, A. and Schwert, G. (1990), 'Alternative models for conditional stock volatility', Journal of Econometrics 45, 267-290.

Payne, R. and Vitale, P. (2003), 'A transaction level study of the effects of central bank intervention on exchange rates', Journal of International Economics 61(2), 331-352.

Pitt, M. K. and Shephard, N. (1999), 'Filtering via simulation: Auxiliary particle filters', Journal of the American Statistical Association 94, 590-599.

Sarno, L. and Taylor, M. P. (2001), 'Official intervention in the foreign exchange market: is it effective and, if so, how does it work?', Journal of Economic Literature 39, 839-868.

Shephard, N. and Pitt, M. K. (1997), 'Likelihood analysis of non-gaussian measurement time series', Biometrika 84, 653-667.

Tims, B. and Mahieu, R. J. (2003), A range-based multivariate model for exchange rate volatility, ERIM Report Series ERS-2003-022-F\&A, ERIM, Rotterdam. 